\title{
Investigating fracture failure in origami-based sheet metal bending
}

\author{
Muhammad Ali Ablat ${ }^{1}$, Ala'aldin Alafaghani ${ }^{1}$, Jian-Qiao Sun ${ }^{1}$, Chetan Nikhare ${ }^{2}$, Ala Qattawi ${ }^{3, *}$
}

\footnotetext{
${ }^{1}$ Mechanical Engineering Department, University of California, Merced, 5200 Lake Rd, Merced, CA 95343, USA

${ }^{2}$ Mechanical Engineering, The Pennsylvania State University, The Behrend College, Erie, PA, 16563, USA

${ }^{3}$ Mechanical, Industrial \& Manufacturing Engineering Department, University of Toledo, $2801 \mathrm{~W}$. Bancroft St., Toledo, OH 43606, USA

*Corresponding author, ala.qattawi@utoledo.edu
} 
Abstract

Origami-based sheet metal (OSM) bending is a promising new die-free folding technique for sheet metal. OSM bending principle is based on deforming the material along a pre-defined fold line, which is determined using material discontinuity (MD) produced by laser or waterjet cutting. The objective of this work is to study and evaluate the fracture in OSM bending under the influence of various MD types, kerfto-thickness $(\mathrm{k} / \mathrm{t})$ ratios, and sheet thicknesses. The research goal is to provide information on selecting an optimized k/t ratio and type of MD that allows for fracture-free bending. Four different ductile fracture criteria (DFC) are used and calibrated from experimental data to forecast fracture. The DFC calibration is used to produce a set of critical damage values (CDV) for assessing the possibility of fracture in the OSM bending. In addition, the study provides fracture evaluation using finite element analysis (FEA) integrated with experimental cases for a broader range of OSM bending parameters and MDs. The results demonstrated that an MD with a higher $\mathrm{k} / \mathrm{t}$ ratio is less likely to fracture during the OSM bending, whereas a higher sheet thickness increases the possibility of fracture. Furthermore, the study identifies the $\mathrm{k} / \mathrm{t}$ ratio limit that ensures successful bending without fracture and categorizes MD types into two groups based on fracture likelihood. The fracture in the first group is dependent on the limiting $\mathrm{k} / \mathrm{t}$ ratio, whereas the possibility of fracture in the second group is independent of the $\mathrm{k} / \mathrm{t}$ ratio due to its topology.

Keyword: Sheet Metal Forming; Finite Element Analysis (FEA); Ductile fracture; Origami-based sheet metal (OSM) bending.

\section{Introduction}

1.1 Origami-based sheet metal bending

Origami is a paper-folding art in Japanese culture where a three-dimensional (3-D) structure is formed from a flat two-dimensional (2-D) sheet of paper. Folding or bending is the only operation in this process. Origami principles inspire applications in many fields including mechanical engineering [1]. As the origami concept is being used in more fields, it opened new research directions while presenting challenges as well. One of such challenges is implementing the origami concept for thick, rigid material to form 3-D structures since, in general, material thickness in origami is assumed to be zero. To overcome the thickness accommodation, researchers proposed various techniques each with its strengths and applicability[2]. One of the techniques highlighted, for instance, is the offset panel technique presented by Edmondson et al [3], in which all the rotational axes and the zero-thickness model lie on the same plane in both unfolded and flat-folded states. This allows panels to move individually without intersecting other panels. However, this technique requires adding additional geometry for the offset. Crampton et al [4] also demonstrated the viability of using sheet metal with the thickness accommodation techniques. They showed how offset panel technique and hinge shift technique were used to create sheet metal square-twist mechanism. Wu and You [5] proposed a two-layer solution to the challenge of flat foldability of a shopping bag with a rectangular base using rigid materials. It demonstrates the application of origami folding using a non-monolithic flat pattern.

Origami-based sheet metal (OSM) bending is an extension of origami principles to sheet metal forming. It is a bending process that uses pre-determined bending lines to construct a 3-D structure. The OSM bending is enabled by creating material discontinuities (MD). MD can take various forms and shapes and can be fabricated by various means such as progressive stamping, laser, or waterjet cutting. Many researchers proposed different types of MD entities [6-9]. Figure 1 demonstrates twelve possible MD topologies that are applied on sheet metal. The schematic of the OSM bending operation is illustrated in Figure 2. It shows that a metal sheet with MD is held between the support and the blank holder. The support is fixed, and 
pressure is applied on top of the blank holder to hold the sheet. The punch is located at a distance (g) away from the edge of the blank holder (or support). Bending occurs with the motion of punch in the $\mathrm{X}$ and negative Y direction, simultaneously. This process also eliminates the need for a die, which is a significant advantage compared to conventional sheet metal bending techniques that require a costly die/mold set [10].

The OSM bending is first investigated from the viewpoint of efficiency of folding (unfolding) metal sheets to a given 3-D structure. This problem is addressed by developing an algorithm to determine the best flat pattern from which the 3-D structure can be constructed [11]. The work developed an approach to evaluate a flat pattern unfolding in terms of a topological analysis, geometrical analysis, stress-based analysis, and potential application of fold forming in the mass production of sheet metal parts. Qattawi et al. [12] presented flat pattern tools derived from zero thickness sheets that can be applied to sheet metal products. The analysis identified all possible flat patterns that transform into the same 3-D structure. It also selected the most optimal flat pattern among all possible patterns as a next step. Qattawi et al. [13] also developed a metric that assists in selecting the most optimal flat pattern in terms of material utilization, cost, and ease of manufacture and handling.

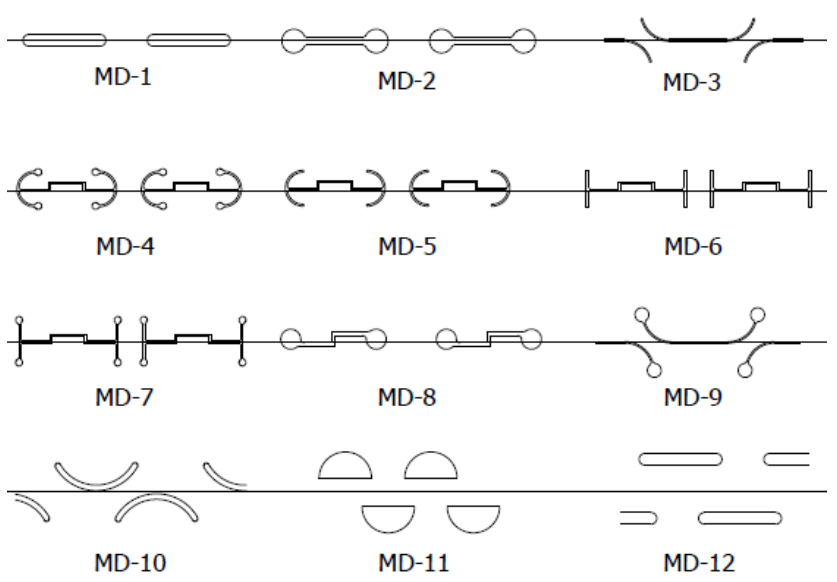

Figure 1 Various MD patterns proposed in the literature [6-9]

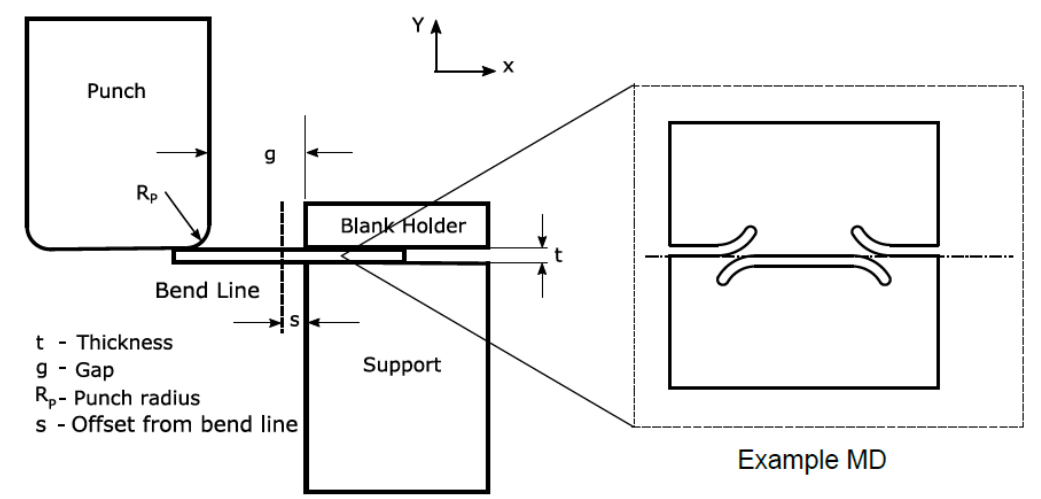

Figure 2 OSM bending configuration. Inset image shows the top view of sheet metal [7-9]

Another direction of research in the OSM bending has been replacing conventional manufacturing approaches and reducing assembly time compared to traditional manufacturing processes where structures are constructed by welding multiple components. The objective of the studies in this direction is to achieve die-free forming with lower manufacturing energy requirements. In this regard, Venhovens et al. [14] showcased the viability of replacing metal stamping with the OSM bending and reducing the cost of vehicle 
body-in-white structure. Shi et al. [15] presented an alternative approach to manufacture conventional thinwalled steel structures using the OSM bending. The study concluded that folding with OSM bending can avoid the complexity encountered in folded structure analysis. Shi et al [16] also characterized rotational stiffness for OSM bending operation. The study proposed a rotational stiffness response prediction model under moment loading for steel structures constructed by OSM bending. Ablat and Qattawi [7] investigated the bending force requirement, the accuracy of bending, and stress magnitude when an OSM sheet is placed in the wiping die bending process. The results showed that MDs reduced bending force requirement and that MDs reduced springback after bending. Further, Ablat and Qattawi [8] conceptualized OSM bending process. They studied associated parameters to the OSM bending process and design of MDs. It was found that stress level along the bending line is dependent on the size of the curvature radius at the end of MD. Hence, a larger kerf-to-thickness (k/t) ratio is recommended to mitigate stress levels. Further, Ablat et al. [9] presented an experimental and analytical study for modeling the OSM bending force. In this study, a prediction model for OSM bending force was proposed. The prediction model revealed a shape factor representing the effect of MD topology.

\section{2 kerf-to-thickness $(\mathrm{k} / \mathrm{t})$ ratio}

While the MD enables the bending and deformation of the sheet metal along the desired bend line, the impact of the $\mathrm{k} / \mathrm{t}$ ratio on MD performance is not completely understood. More specifically, the effect of the $\mathrm{k} / \mathrm{t}$ ratio on the bending process and fracture has not been studied.

In this study, the term " $\mathrm{k} / \mathrm{t}$ ratio" is defined as the ratio of kerf to the thickness of the sheet. The kerf is the width of the material being removed by the cutting tool along the MD geometrical outline. The kerf and other parameters on an OSM sheet are illustrated in Figure 3.

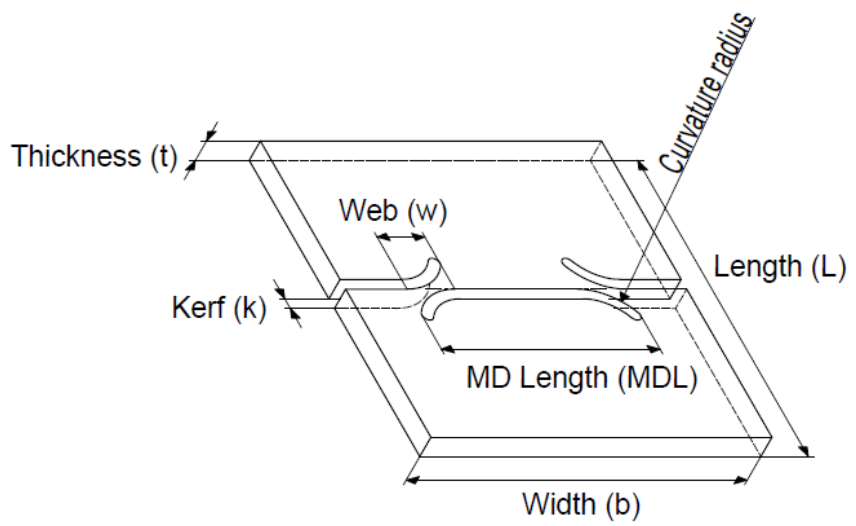

Figure 3 Kerf and other parameters of an OSM sheet

The previous work [8] concluded that the $\mathrm{k} / \mathrm{t}$ ratio of the MD is critical for achieving successful bending without fracture. It was shown that the stress magnitude in the OSM bending is affected by the $\mathrm{k} / \mathrm{t}$ ratio of $\mathrm{MD}$, where a larger $\mathrm{k} / \mathrm{t}$ ratio is recommenced to have a lower magnitude of stress in the OSM bending. Hence smaller k/t ratio results in a higher magnitude of stress, which can cause fracture and tear during the bending process. For instance, the smallest $\mathrm{k} / \mathrm{t}$ ratio investigated in [8] was 0.2 , which is $0.32 \mathrm{~mm}$ on a 1.6 $\mathrm{mm}$ thick sheet of Aluminum-2036-T4. The Von-Mises stress magnitude generated on MD-2 type (see Figure 1) is $12.4 \%$ higher on a $0.2 \mathrm{k} / \mathrm{t}$ ratio compared to a $\mathrm{k} / \mathrm{t}$ ratio of 0.3 . Conversely, if a large $\mathrm{k} / \mathrm{t}$ ratio of MD is used, it may undermine the purpose of OSM bending, and bending may not occur at the desired bending line. The study carried out by Nikhare [17] showed that a large $\mathrm{k} / \mathrm{t}$ ratio of MD leads to an undesired bending that was not along the pre-determined bending line. Further, an experimental and analytical OSM 
bending force model was developed to predict the required bending force [8]. In this work, the fracture of OSM samples occurred during the concept testing phase. From the observations, it can be hypothesized that the proper selection of the $\mathrm{k} / \mathrm{t}$ ratio for a given MD is a critical factor that influences the success of the OSM bending operation in terms of bending accuracy and avoiding failure by fracture. However, previous studies did not provide a quantitative approach to evaluate the possibility of a fracture during the OSM bending process. Investigating the desired $\mathrm{k} / \mathrm{t}$ ratio of MD for OSM bending enables the higher success of the forming operation. Hence, this study quantitatively identifies the impact of the $\mathrm{k} / \mathrm{t}$ ratio on sheet metal fracture that occurs during bending using ductile fracture criteria (DFC).

2. Ductile Fracture

Generally, failure in sheet metal forming is assessed using forming limit diagrams (FLD) [18-21]. The process of constructing a forming limit curve is shown using the strain distributions obtained from 0.2 in. inter-locking circle grid patterns on blanks. Often, the strain values on the sheet are compared with an empirical failure curve to indicate the proximity of stamping to failure. This approach has become the basis for the FLD. The application of FLD is extended to various problems. For instance, an inter-locking circle grid on sheet metal is used to predict fracture forming limit diagram (FFLD) [22], and FLD is used to evaluate mechanical properties and formability of produced DP steels with different martensite morphologies [23].

However, assessing the failure in OSM bending using FLD raises the question of suitability due to limitations in FLD such as difficulty to determine the onset of necking. In FLD, generally, the strain is measured until necking with different strain paths, and the strain magnitude causing failure is recorded [24]. The FLDs are widely used because they conveniently offer a way to evaluate the maximum amount of deformation that can take place during a sheet forming before the material becomes plastically unstable. However, the FLDs are not suitable for applications where the material doesn't exhibit a clear necking before fracture [25], as observed in a biaxial test [26, 27] and incremental sheet forming process [28]. OSM bending does not exhibit a necking and thinning of the sheet. Therefore, the FLDs are not a suitable choice to predict a fracture in OSM bending.

In bending-dominated processes such as hemming and air bending, the failure mechanism is not controlled by necking [29]. This is due to the fact that it is not possible to form a necking in the pure bending process due to the compression stress at the concave side of the sheet, which is below the limit for initiation of a necking instability. The ductile fracture should be used as the failure criteria [30,31] on such failure. Since OSM bending is also a bending dominant process, this study utilizes various DFC to predict the occurrence of a fracture during OSM bending.

3. Fracture prediction method using DFC

The available DFC on sheet metal fracture can be grouped into two general categories [30], those are coupled and uncoupled DFC. The coupled DFC models focus on microscopic damage evolution to model fracture. The models are based on nucleation, growth, and coalescence of the crack until fracture. The uncoupled DFC is phenomenological relation that models the fracture macroscopically. This approach gain popularity due to its simplicity and the fewer coefficients that need to be determined compared to coupled DFC.

Most of the uncouples DFC models use the function form of $\int_{0}^{\bar{\varepsilon}_{f}} f(\sigma, \bar{\varepsilon}) d \bar{\varepsilon}$, which represents plastic work. The function, $f$, involves various stress invariants. The uncoupled fracture criteria state that fracture occurs when accumulated plastic strain reached a critical value. 
Based on these facts, uncoupled DFC is used in this study. Specifically, the DFC was proposed by Cockcroft and Latham [32, 33], Brozzo [34, 35], Ayada [36, 37], and Rice and Tracy [38, 39]. The specific forms of these DFC are given in Eq. (1)-(4), where Eq. (1)-(4) represent Cockcroft and Latham, Brozzo, Ayada, Rice, and Tracy, respectively.

$$
\begin{aligned}
& D_{1}=\int_{0}^{\bar{\varepsilon}_{p}^{f}} \frac{\sigma_{1}}{\sigma_{e q}} d \bar{\varepsilon}_{p} \\
& D_{2}=\int_{0}^{\bar{\varepsilon}_{p}^{f}} \frac{2 \sigma_{1}}{3\left(\sigma_{1}-\sigma_{h}\right)} d \bar{\varepsilon}_{p} \\
& D_{3}=\int_{0}^{\bar{\varepsilon}_{p}^{f}} \frac{\sigma_{h}}{\sigma_{e q}} d \bar{\varepsilon}_{p} \\
& D_{4}=\int_{0}^{\bar{\varepsilon}_{p}^{f}} \exp \left(\frac{3}{2} \frac{\sigma_{h}}{\sigma_{e q}}\right) d \bar{\varepsilon}_{p}
\end{aligned}
$$

where $D_{i}(\mathrm{i}=1,2,3,4)$ is damage value corresponding to the selected four DFC, $\sigma_{j}(j=1,2,3)$ are principal stresses, $\sigma_{e q}$ is equivalent stress, $\sigma_{h}$ is hydrostatic stress, $\bar{\varepsilon}_{\mathrm{p}}$ is the equivalent plastic strain, and $\bar{\varepsilon}_{\mathrm{p}}^{\mathrm{f}}$ is the equivalent plastic strain at fracture.

As can be seen from Eq. (1)-(4), Cockcroft and Latham criterion [32, 33] argued that that fracture is associated with maximum principal stress $\sigma_{1}$, and equivalent stress $\sigma_{e q}$. The criterion was proposed considering a tensile cylindrical specimen. Therefore, the logic behind the suggestion is that maximum principle stress $\sigma_{1}$ acting at a centerline of cylindrical tensile specimen initiate fracture. The Brozzo criterion $[34,35]$ is dependent on hydraulic stress. Brozzo criterion empirically modified Cockcroft and Latham to fit experimental results because Cockcroft and Latham criterion predicted the strain at fracture lower than experimental values. The Ayada criterion $[36,37]$ depends on the hydrostatic stress $\sigma_{h}$, as well. The Adaya criterion was proposed to predict fracture during the extrusion process. Since the stress state is 3-D in the extrusion process, especially at the location where the center burst occurs, it modified Cockcroft and Latham criterion and introduced hydraulic stress. The Rice and Tracy criterion [38, 40] has an exponential relation with the hydrostatic stress $\sigma_{h}$. Rice and Tracy criteria is proposed based on investigation of ductile fracture for porous materials under various stress triaxialities.

These DFC are chosen because they need only one parameter to calibrate, and this allows for a relatively straightforward calibration process. For all these DFC, fracture happens when the parameters $D_{i}$ reaches a critical damage value (CDV), which can be identified by uniaxial tension test and corresponding finite element analysis (FEA).

The complete workflow developed to predict the fracture in OSM bending in this work is shown in Figure 4. The workflow consists of three main steps, which are DFC calibration, FEA of OSM bending, and OSM bending experiment. The proposed approach relies on the calibration of DFC and using computational modeling through FEA and finally experimental approach to provide a comparative analysis of the failure strain. As can be seen in Figure 4, the three main steps are interconnected to provide a comprehensive prediction using computational, and experimental studies.

In the first step, the four DFC are calibrated to compute the CDVs that represent each of the four DFC. The CDVs are then used as a benchmark when predicting the possibility of a fracture. During this process, the CDVs are determined by the entire stress-strain characteristics of the material from a tensile test. The stressstrain characteristics until necking are determined from the uniaxial tensile test on a standard sheet type 
sample. Because deformation mode changes after necking in the uniaxial tensile test, the stress-strain relationship beyond necking is determined with the help of an iterative finite element process of the same tensile test.

In the second step, FEA of OSM bending is performed to calculate the damage values (DVs) for different types of MDs, different $\mathrm{k} / \mathrm{t}$ ratios, and different sheet metal thicknesses. The DVs represent the damage value of each case considered in this study. Then, DVs are compared against CDVs to determine the possibility of a fracture occurring during the OSM bending process.

Finally, the FEA of OSM bending is experimentally validated by comparing the equivalent strain results from FEA to experimental equivalent strain measurement using digital image correlation (DIC) at the top surface of the OSM sheet. This step assurance the accuracy of the FEA performed in the second step.

In this study, four different MDs are selected for the investigation. They are MD-1, MD-2, MD-3, and MD5 , respectively, shown in Figure 1. These MD types are chosen for the study since they are the basis for other MD types. Previous work [7-9] implied that each MD may fracture at a different $\mathrm{k} / \mathrm{t}$ ratio for the same sheet material type and thickness. Hence, a different set of $\mathrm{k} / \mathrm{t}$ ratios is chosen for each MD as listed in Table 1.

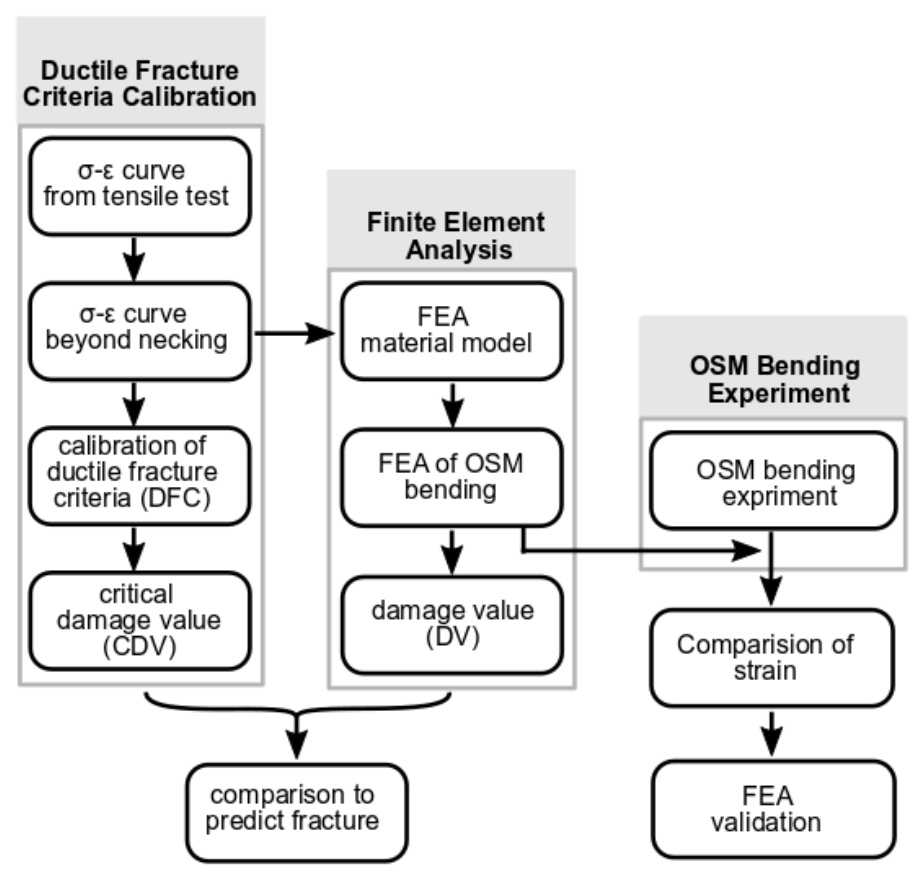

Figure 4 Proposed workflow of fracture prediction in OSM bending presented in this work

Table 1 The chosen k/t ratio, thickness, and MD type for the fracture analysis in this work

\begin{tabular}{cccc}
\hline MD Type & $\mathrm{k} / \mathrm{t}$ ratio* & $\begin{array}{c}\text { Thickness } \\
{[\mathrm{mm}]}\end{array}$ & Material \\
\hline MD-1 & $0.3,0.5,1,1.5,2$ & 1.6 & Aluminum \\
MD-2 & $0.3,0.5,0.7$ & 2.3 & Alloy 6061-O \\
MD-3 & $0.2,0.3,0.4,0.5$ & 3.2 & \\
MD-5 & $0.2,0.3,0.4,0.5$ & \multicolumn{2}{l}{} \\
\hline *k/t ratio: the ratio of kerf to the thickness of the sheet. The kerf is the width of the material being \\
removed by the cutting tool along the MDs geometrical outline.
\end{tabular}


Three-level thicknesses are taken into consideration to determine if the same $\mathrm{k} / \mathrm{t}$ ratio causes fracture at a different thickness. The material used for this study is aluminum alloy 6061 temper O, denoted as AA6061-O below.

\section{Calibrating DFC}

4.1 Determining the stress-strain curve beyond necking

The calibration process of DFC carried in this work refers to the process of determining the stress-strain relationship of AA-6061-O prior to and post necking. The calibration also determines the CDVs for the chosen DFC listed in Eq. (1)-(4).

This procedure is carried out using a standard tensile test as outlined in the ASTM testing standard [41] and iterative FEA studies of the same tensile test setup. The steps used in this work to calibrate the DFC are outlined below:

1. A uniaxial tensile test is performed on AA-6061-O until fracture. During the test, forcedisplacement data is collected. The stress-strain characteristics until necking is obtained from the test.

2. The post-necking stress-strain values are estimated based on the weighted average method [42]. The stress-strain values until fracture are fed into the FEA model of the uniaxial tensile test to define the material behavior for AA-6061-O.

3. FEA for the uniaxial tensile test is performed iteratively until the force-displacement from the FEA model matches that of the uniaxial tension test in step 1.

4. The critical damage values are calculated for each of the four DFC once the force-displacement curve from the experimental and FEA match in step 3.

During the uniaxial tensile test, the sheet specimen is prepared according to ASTM testing standard [41] along the rolling direction of the material with the dimension shown in Figure 5. The specimen thickness is 14 gauge $(1.6 \mathrm{~mm})$. In the test, the elongation of the specimen is controlled by the speed of the crosshead motion. Before yielding, the speed of the load cell is set to $1.23 \mathrm{~mm} / \mathrm{s}$ and then changed to $10 \mathrm{~mm} / \mathrm{s}$ for the post-yielding phase. The tensile test is carried on Instron universal testing machine 3369 . The loads and extension data are collected from the test.

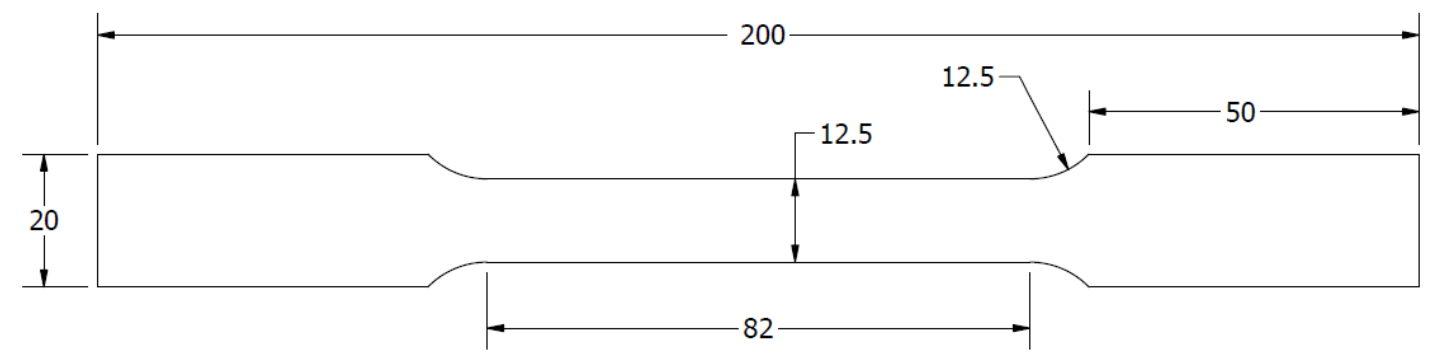

Figure 5 Tensile test specimen of OSM experiment. Dimensions are in $\mathrm{mm}$.

The FEA of the tensile test is performed using ANSYS. Since the bending occurs along the rolling direction of sheet metal, the ratio of strain in thickness and width direction stays constant, therefore, anisotropy was not considered in the FEA model. The material is assumed to follow the Von Mises yield criterion and associated flow rule. The plasticity model for AA-6061-O is elastic-plastic with multi-linear isotropic hardening. To reduce computing time, one-fourth of the sample is modeled by considering only half-width and half-thickness due to the symmetry in the sample. The symmetry boundary condition is applied along the length and thickness of the specimen. One end of the specimen is fixed, and a displacement load is 
applied on the other end. The magnitude of the displacement load is $20.8 \mathrm{~mm}$, which is the same displacement measured from the tensile test experiment at fracture. In the FEA of the uniaxial tensile test, the fracture is assumed to take place when the displacement reaches the value of $20.8 \mathrm{~mm}$. To ensure the necking happens at the center of the specimen, a small defect on the two sides of the specimen is introduced $[43,44]$, which concluded that a tapered uniaxial tension test specimen in the FEA can provide an effective stress-strain curve to capture the disuse necking at the center of the specimen. The geometry of the specimen is discretized with 8-node Hexa-linear elements. Mesh size at the center was much finer and it is gradually coarsened towards the two ends of the sample. Mesh on the tensile test specimen is shown in Figure 6.

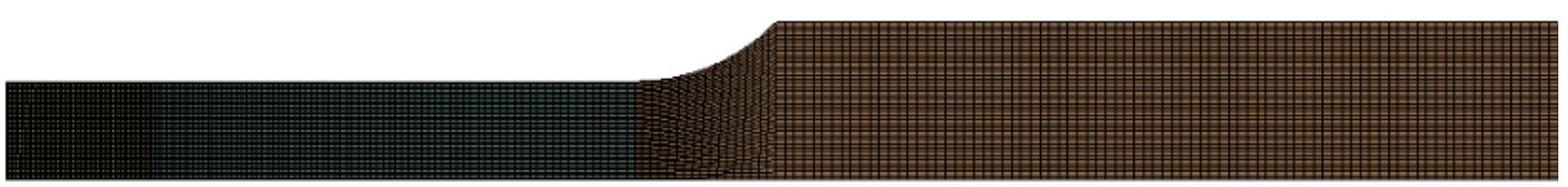

Figure 6 Meshing of the half (from center to the end) tensile test specimen

The stress-strain relationship prior to necking is obtained from the recorded load-displacement data in the uniaxial tensile test. The stress-strain relationship beyond necking is estimated using the weighted average method [42], which uses Eq. (5) iteratively to determine the stress-strain relationship beyond necking.

$$
\sigma=\sigma_{u}\left[\mathrm{w}\left(1+\epsilon-\epsilon_{u}\right)+(1-\mathrm{w})\left(\epsilon / \epsilon_{u}\right)^{\epsilon_{u}}\right]
$$

where $\sigma$ is true stress, $\sigma_{u}$ is ultimate true stress, $\epsilon$ is the true strain, $\epsilon_{u}$ is the ultimate true strain, and $w$ is the weight factor.

The iteration continued until force-displacement data from the FEA of the tensile test matches the experimental force-displacement curve. After the iterations are completed, the weight factor, $w$, is determined to be 0.865 . The final force-displacement curve matches the tensile test closely and is shown in Figure 7. The identified stress-strain data in Figure 8 is then provided as an input for the multilinear isotropic hardening material model of AA-6061-O in the OSM bending FEA studies.

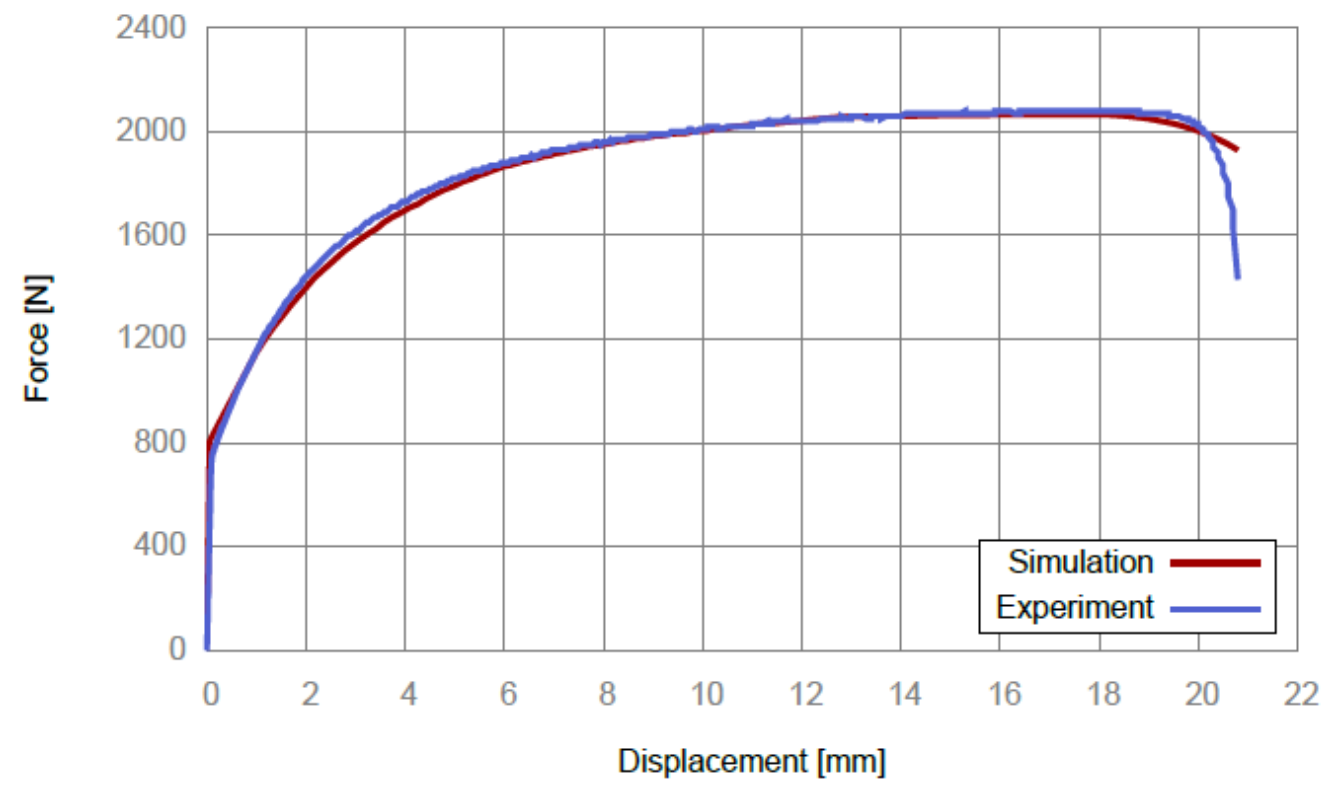

Figure 7 Force-displacement curve from tensile test and FEA model 


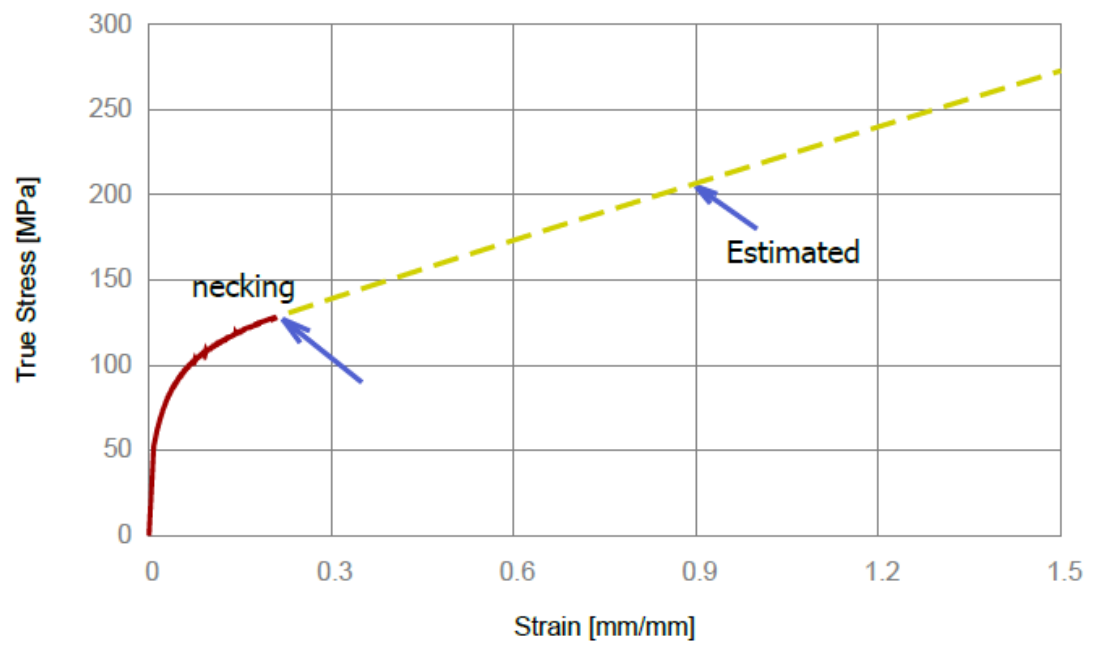

Figure 8 True Stress-Strain curve is extended by the weighted average method. This curve is used as input to AA-6061-O material model definition in FEA

\subsection{Calculating critical damage values for DFC}

The CDVs for the four DFC are calculated from the FEA of the uniaxial tensile test. The CDVs correspond to the accumulated damage value of the material until fracture. For each increment of the load step in the FEA of the uniaxial tensile test, the necessary fields such as the maximum principle stress, equivalent stress, hydrostatic stress, and equivalent plastic strain, are extracted using an Ansys APDL code. The extracted field data is then used to integrate according to Eq. (1)-(4). The integration is performed using the trapezoid integration rule in MATLAB. The identified CDV at fracture from the chosen DFC are tabulated in Table 2. Accumulation of CDV over simulation step increments is shown in Figure 9.

Table 2 CDV (critical damage value) at fracture from chosen DFC

\begin{tabular}{ccccc}
\hline DFC Criteria & $\begin{array}{c}\mathrm{D}_{1} \\
\text { (Cockcroft and Latham) }\end{array}$ & $\begin{array}{c}\mathrm{D}_{2} \\
\text { (Brozzo) }\end{array}$ & $\begin{array}{c}\mathrm{D}_{3} \\
\text { (Adaya) }\end{array}$ & $\begin{array}{c}\mathrm{D}_{4} \\
\text { (Rice and Tracy) }\end{array}$ \\
\hline CDV & 0.607 & 0.6107 & 0.214 & 1.017 \\
\hline
\end{tabular}

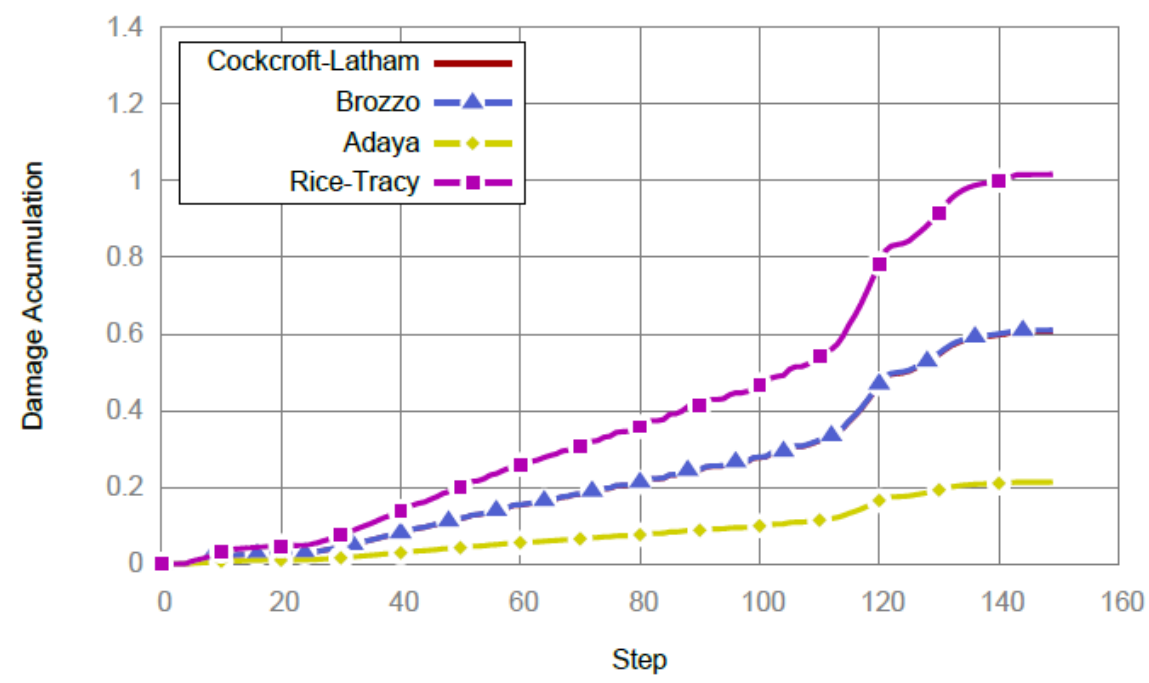

Figure 9 Damage value accumulation over tensile test FEA step increment. Note that the Brozzo and Cockcroft-Latham DFC results are coinciding on the graph. 


\section{FEA of OSM Bending}

A series of OSM bending FEA is performed to calculate the DVs for each of the MDs under different $\mathrm{k} / \mathrm{t}$ ratios and thicknesses. The FEA is set up in a configuration identical to the setup shown in Figure 2. Taking all MD types, $\mathrm{k} / \mathrm{t}$ ratios, and sheet thickness listed in Table 1 into account, there are 48 cases in total as tabulated in Table 3. The case name in Table 3 starts with the MD type followed by the thickness of the sheet, then the $\mathrm{k} / \mathrm{t}$ ratio of the MD indicated by " $\mathrm{k}-\mathrm{t}$ ", and a number representing the $\mathrm{k} / \mathrm{t}$ ratio. All of the OSM bending FEA cases use the same configuration parameters, i.e., $g=23 \mathrm{~mm}, \mathrm{~s}=3 \mathrm{~mm}, \mathrm{Rp}=3 \mathrm{~mm}$, where $\mathrm{g}$ is the gap between the punch and edge of the support (blank holder), $\mathrm{s}$ is the offset distance, $\mathrm{R}_{\mathrm{p}}$ is the punch radius.

The sheet size is $50(\mathrm{~mm}) \times 50(\mathrm{~mm})$. The MDs are applied in the middle of the sheet. The dimensions for the sheet and MDs are illustrated for the $\mathrm{k} / \mathrm{t}$ ratio of 0.3 in

Figure 10 .

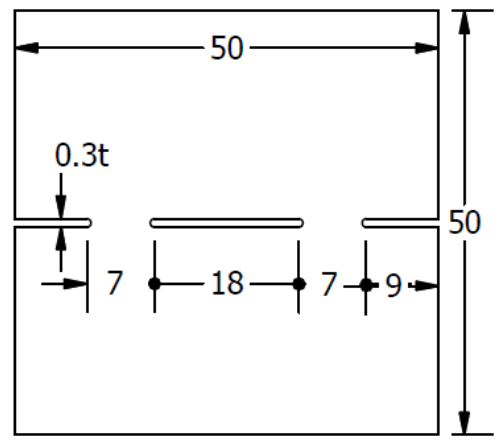

(a) $\mathrm{MD}-1$

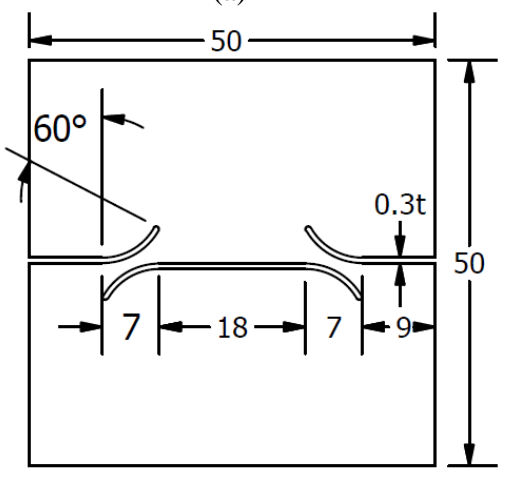

(c) MD-3

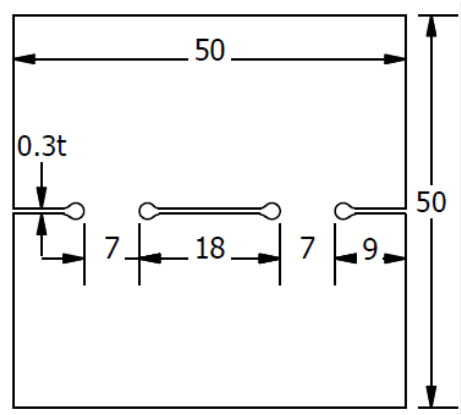

(b) MD-2

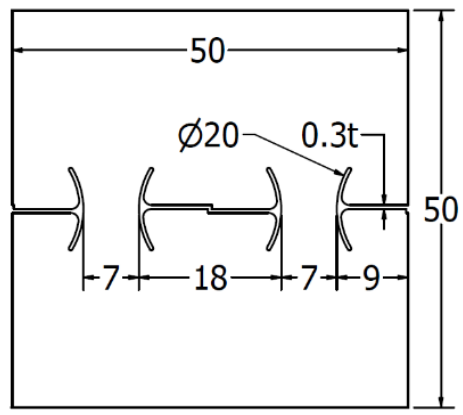

(d) MD-5

Figure 10 Dimensions of the sheet and MDs with a k/t ratio of 0.3 included in this study

In the FEA of the OSM bending process, the punch, the support, and the blank holder are modeled as rigid bodies. The sheet is modeled as a deformable flexible body. A four-node rectangular element type is used for all rigid bodies in the FE model. The blank sheet is discretized with 20 node Hexa-dominant elements. To save computing time, only half (for MD-3 and MD-5) or a quarter (MD-1 and MD-2) of the blank sheet geometry is simulated due to geometric symmetry. The meshing of the blank sheets is shown in Figure 11. 
The deformation of the sheet obeys von Mises yield criterion and associated flow rule. A friction coefficient of 0.12 is considered between the sheet and all rigid bodies.

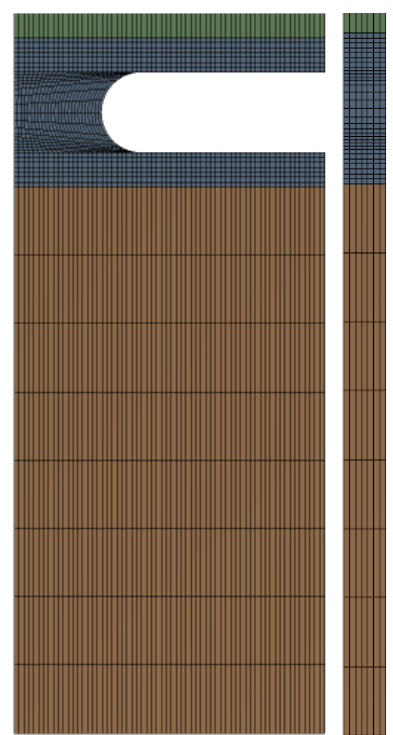

(a)

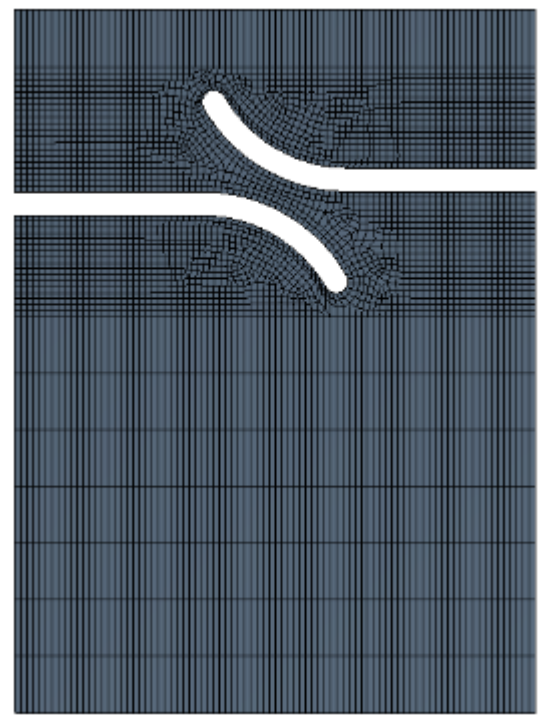

(c)

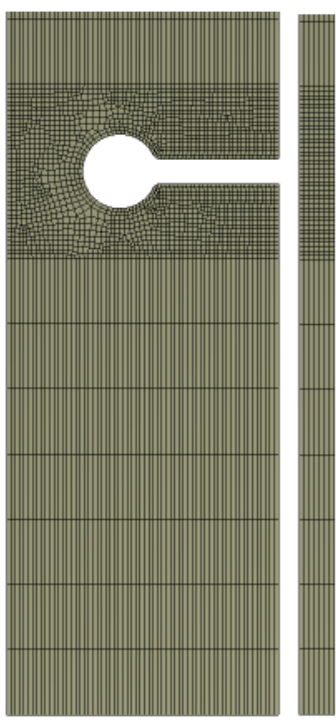

(b)

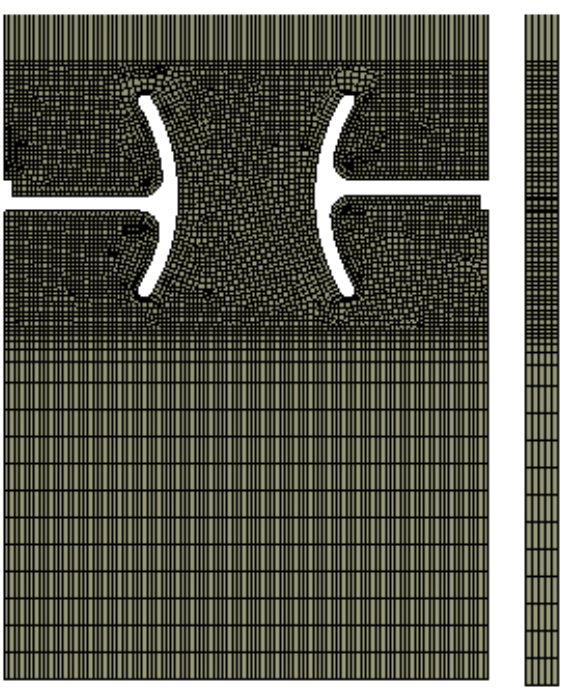

(d)

Figure 11 Mesh along the in-plane and thickness directions. Due to symmetry about bending line located in the middle of MDs, a portion of the meshing on blank sheet geometry is shown here. (a) MD-1; (b) MD-2; (c) MD-3; (d) MD-5

The OSM bending process is simulated in two load steps. The first load step is to apply a pressure load on the blank holder to hold the sheet in the correct position during the bending process. The second load step is to apply a displacement load on the punch along with horizontal and vertical directions to bend it to $90^{\circ}$.

\section{Experimental Validation of FEA for OSM Bending}

An OSM bending device, as shown in Figure 12, is designed in this study to validate the OSM bending FEA results. The bending device consists of a base, sheet holder, bending bar, mounting column, and a pair of rotating links. The base is connected to the mounting column, which is used to position the whole device in a vise. On top of the base, there is a $1 \mathrm{~mm}$ deep slot that precisely matches the width of the OSM sheet 
specimen. The slot also ensures the OSM sheet specimen is placed with a $3 \mathrm{~mm}$ offset distance (s). The base also has a step at the front that guarantees the bending stops at $90^{\circ}$. The sheet holder is placed on top of the sheet sample. The sheet holder fixes the sheet sample through four screws connected to the base. A bending bar is transversely connecting a pair of rotating links that can rotate freely. The bending takes place with the guide of rotating links once the bending bar starts pressing the sheet.

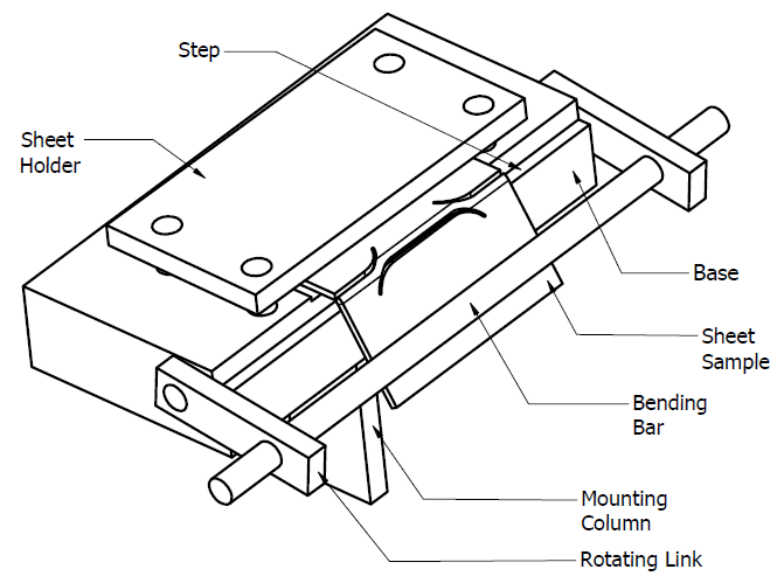

Figure 12 OSM bending device

In the OSM bending experiment, the equivalent strain that occurred on the surface of the OSM sample is analyzed using DIC. The trend of equivalent strain is evaluated over the entire duration of $90^{\circ}$ bending. The trend of equivalent strain variation over the bending angle is then compared to the trend obtained from the FEA of OSM bending.

For the experiment validation, six different cases are selected from the 48 cases listed in Table 3 , which are cases No. 5, 10, 18, 21, 36, and 40. These cases are chosen based on two rules. First, they cover different thicknesses. The second is to select the largest $\mathrm{k} / \mathrm{t}$ ratio among all $\mathrm{k} / \mathrm{t}$ ratios investigated for each MD to increase testing data acquisition accuracy and the field of view for DIC.

Images of the OSM sheet specimen surface are captured by the DIC system with a frequency of four images per second. The equivalent strain field from the images is then computed on the surface of the specimens. Then the maximum equivalent strain on the surface is evaluated with respect to the bending angle. A comparison is made between the experiment data and FEA in terms of equivalent strain magnitude variation over the bending angle, as shown in

Figure 13 - Figure 18. The trend of maxim equivalent strain and bending angle appears to be a linear relationship. The linear relationship is also proved and captured in the experiment, where the curves are mostly linear except for some deviations due to noise and equipment error. Good repeatability is observed when the same case is tested twice. The results can be seen in Figure 19 and Figure 20.

The comparison analysis indicates that FEA is in good agreement with the experiment in general. There are two sources of the discrepancy. First, the noise in the DIC system caused fluctuation in the magnitude of the equivalent strain. The noise depends on stochastic paint quality on the sheet and ambient light. Second, the FEA strains appear larger because the boundary of manually created DIC surface components is slightly smaller than the real surface of the sheet sample. Because the points at the edge have maximum strain. So, FEA strain results appear higher. Considering all these factors, FEA yields a very good agreement with the experiment. 


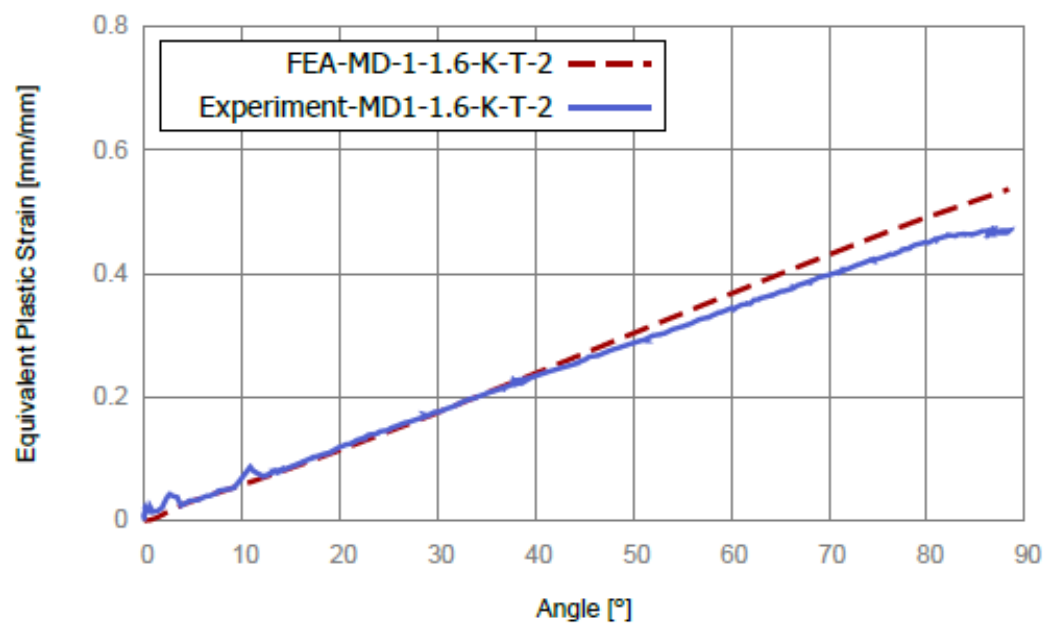

(a)

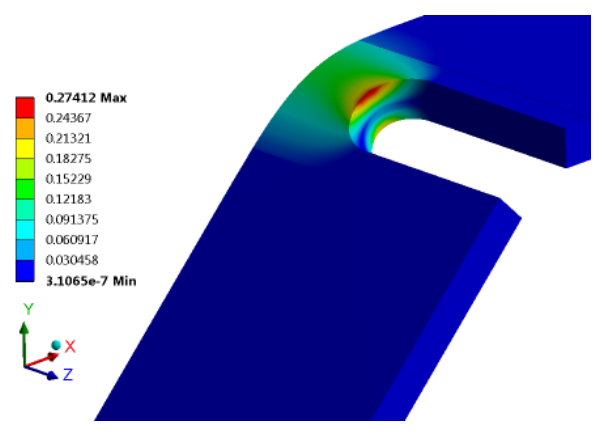

(b)

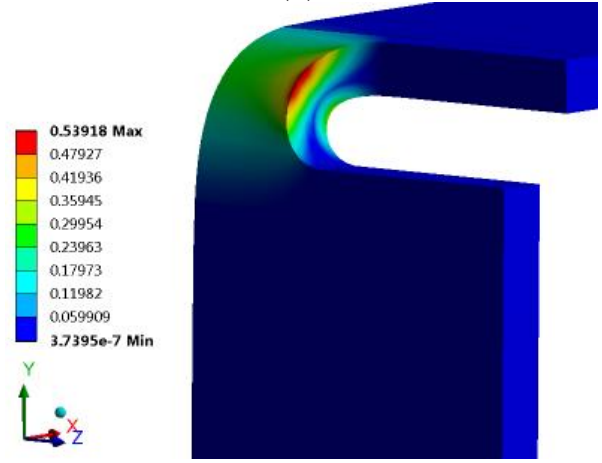

(d)

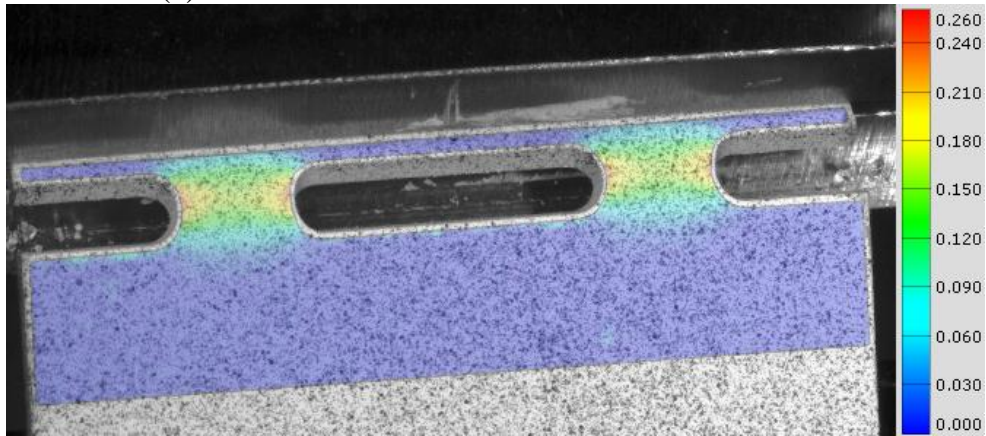

(c)

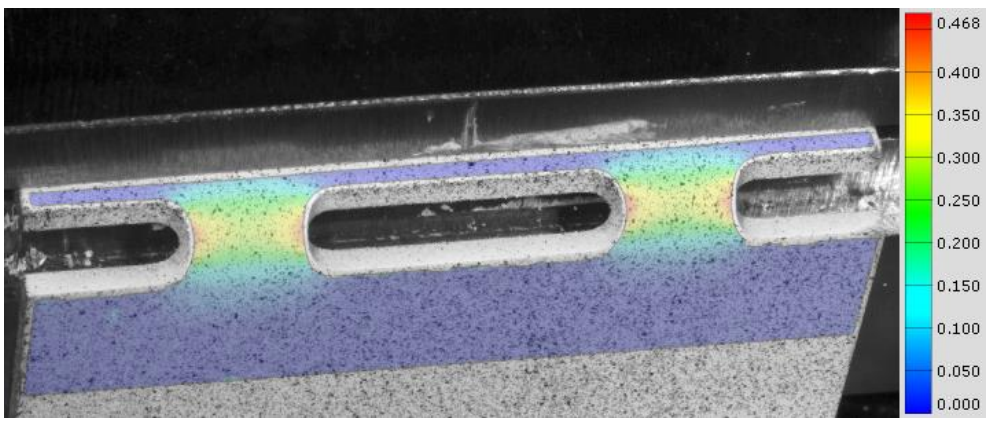

(e)

Figure 13 FEA validation for case No. 5 (MD-1-1.6-K-T-2). (a) equivalent plastic strain comparison between experiment and FEA; (b)FEA equivalent plastic strain field at $45^{\circ}$ bending; (c) experimental equivalent plastic strain field at $45^{\circ}$ bending; (d)

FEA equivalent plastic strain field at $90^{\circ}$ bending; (e) experimental equivalent plastic strain field at $90^{\circ}$ bending. 


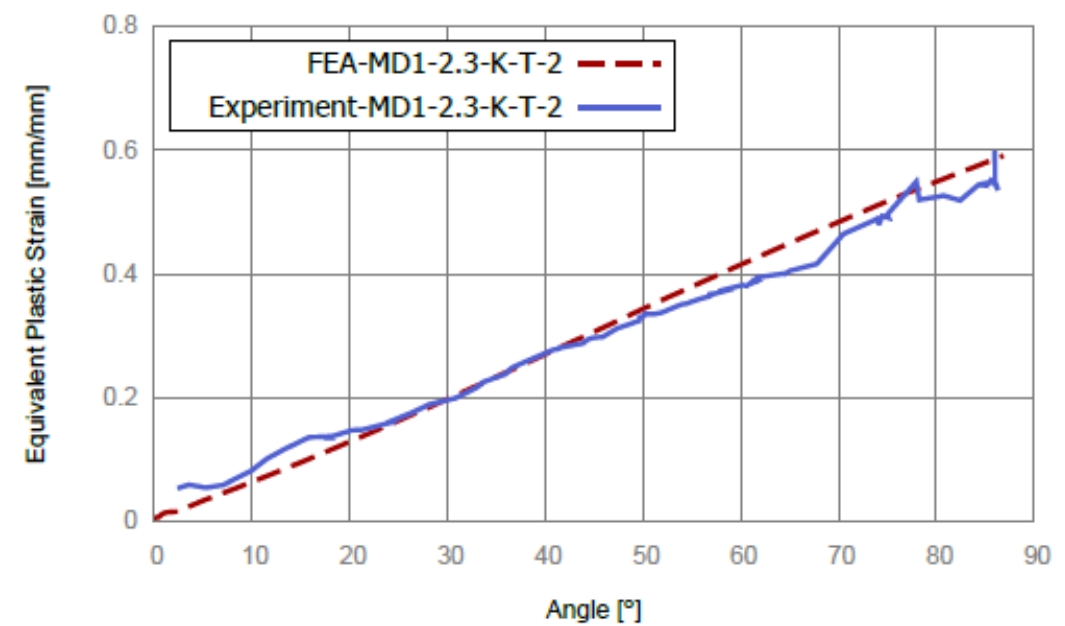

(a)

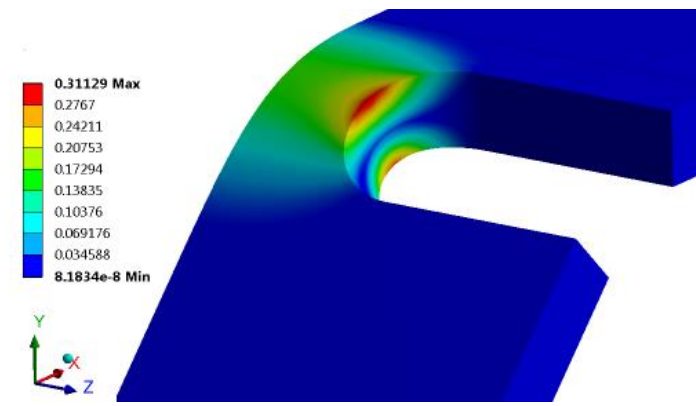

(b)

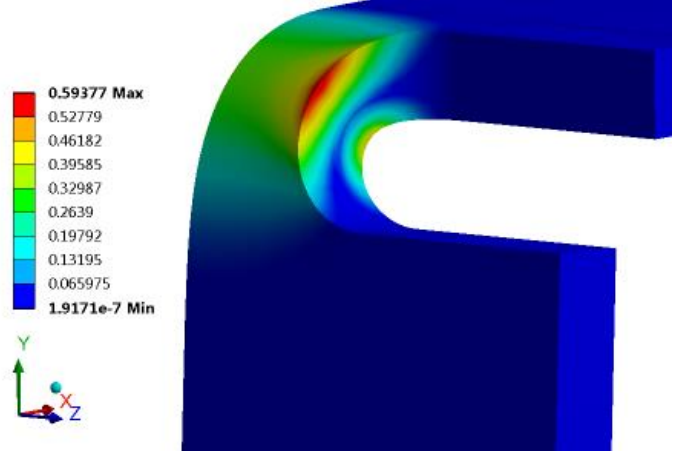

(d)

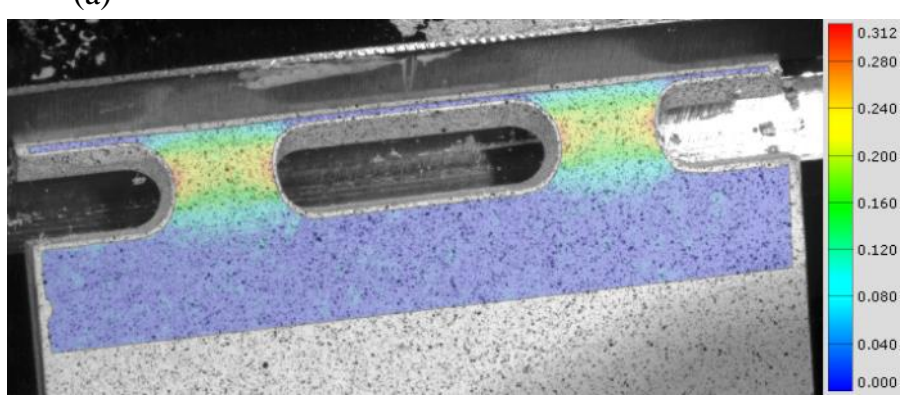

(c)

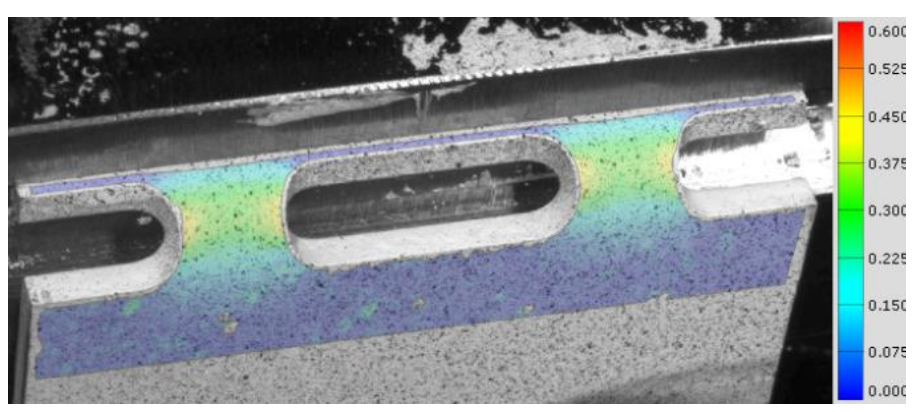

(e)

Figure 14 FEA validation for case No. 10 (MD-1-2.3-K-T-2). (a) equivalent plastic strain comparison between experiment and FEA; (b)FEA equivalent plastic strain field at $45^{\circ}$ bending; (c) experimental equivalent plastic strain field at $45^{\circ}$ bending; (d) FEA equivalent plastic strain field at $90^{\circ}$ bending; (e) experimental equivalent plastic strain field at $90^{\circ}$ bending. 


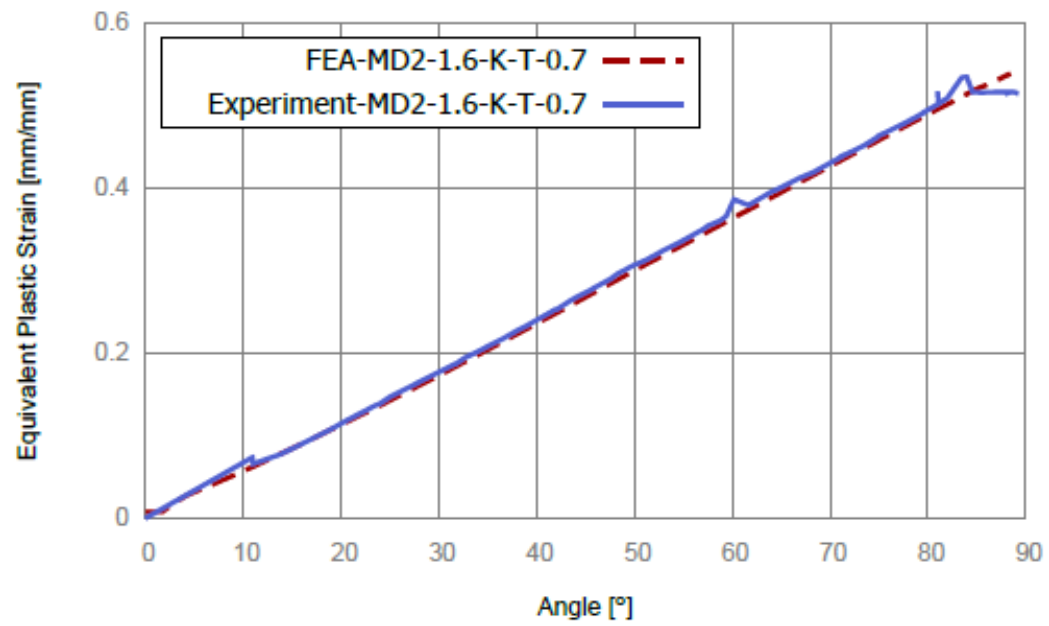

(a)

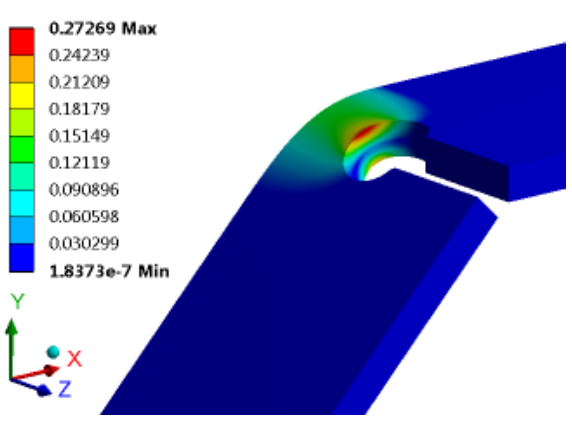

(b)
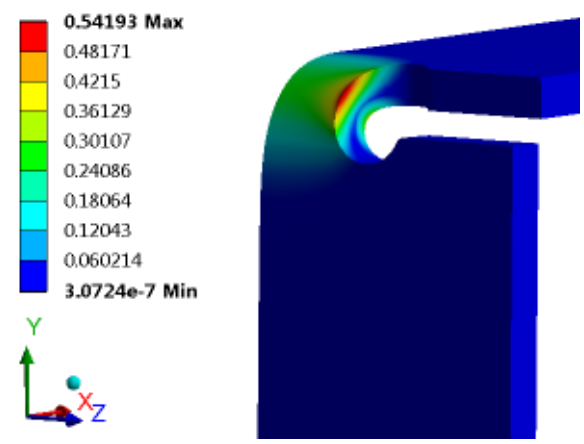

(d)

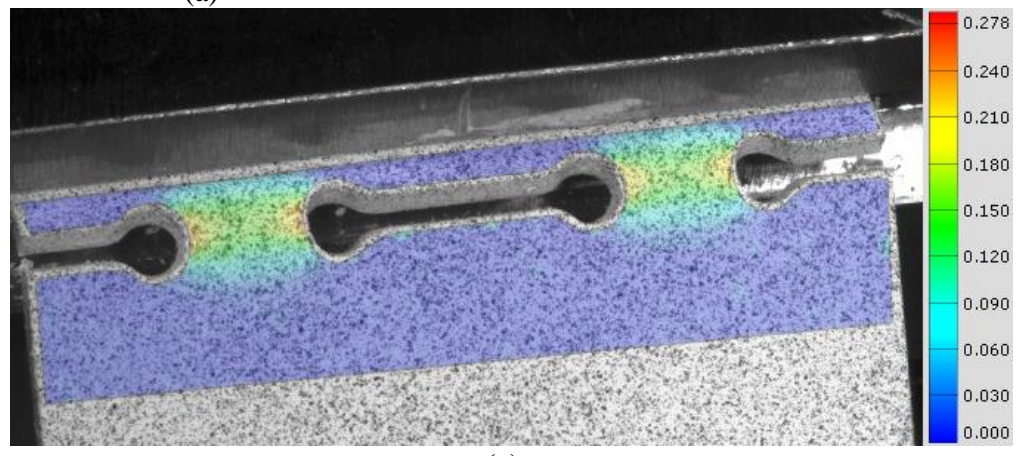

(c)

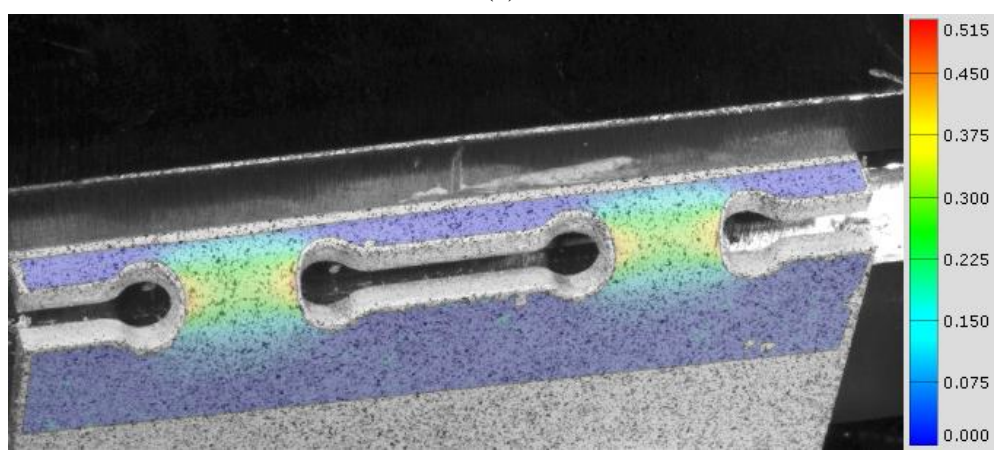

(e)

Figure 15 FEA validation for case No. 18 (MD-2-1.6-K-T-0.7). (a) equivalent plastic strain comparison between experiment and FEA; (b)FEA equivalent plastic strain field at $45^{\circ}$ bending; (c) experimental equivalent plastic strain field at $45^{\circ}$ bending;

(d) FEA equivalent plastic strain field at $90^{\circ}$ bending; (e) experimental equivalent plastic strain field at $90^{\circ}$ bending. 


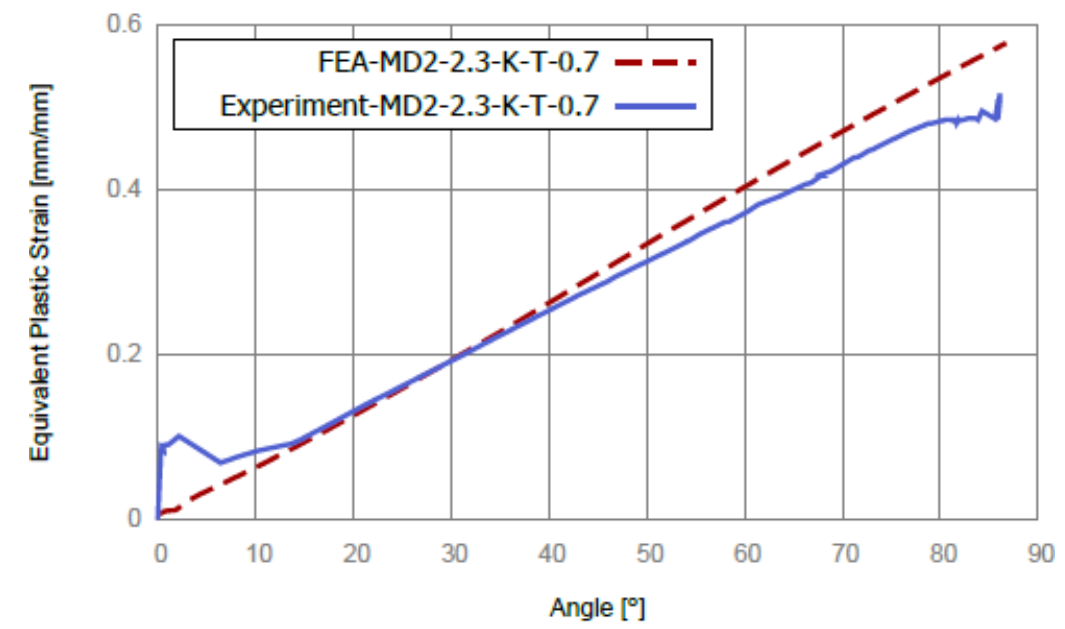

(a)

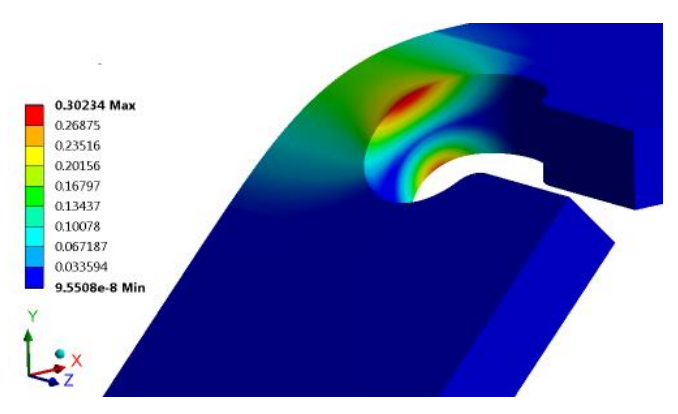

(b)

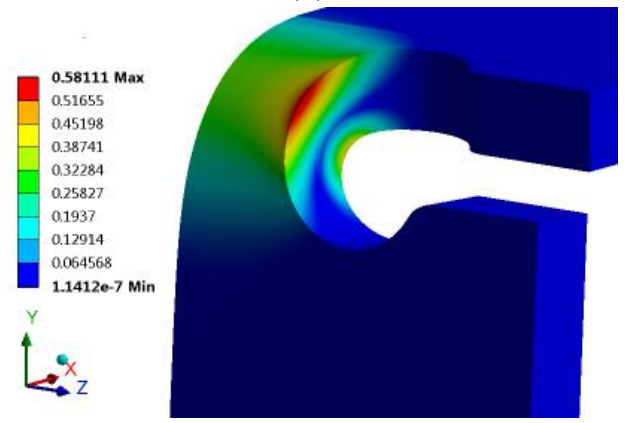

(d)

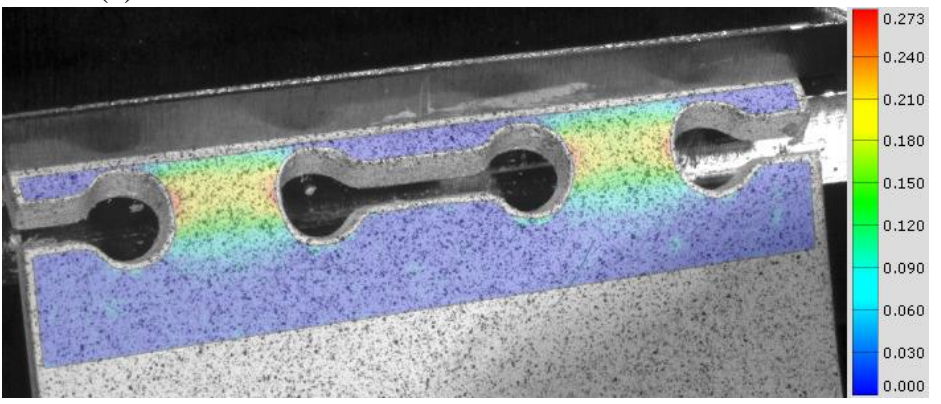

(c)

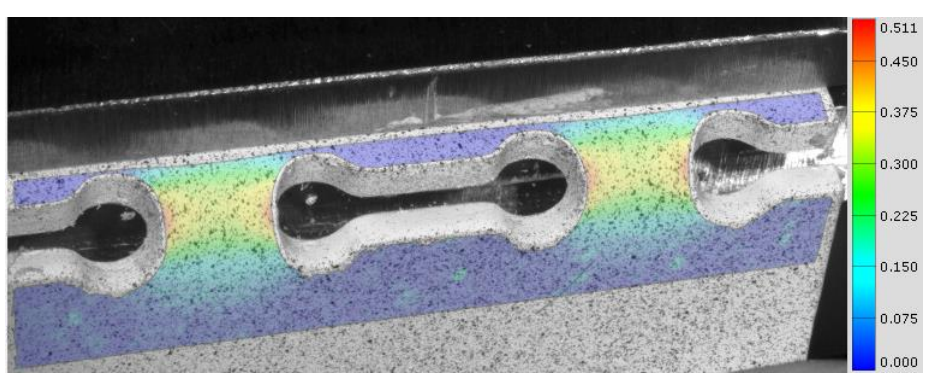

(e)

Figure 16 FEA validation for case No. 21 (MD-2-2.3-K-T-0.7). (a) equivalent plastic strain comparison between experiment and FEA; (b)FEA equivalent plastic strain field at $45^{\circ}$ bending; (c) experimental equivalent plastic strain field at $45^{\circ}$ bending;

(d) FEA equivalent plastic strain field at $90^{\circ}$ bending; (e) experimental equivalent plastic strain field at $90^{\circ}$ bending. 


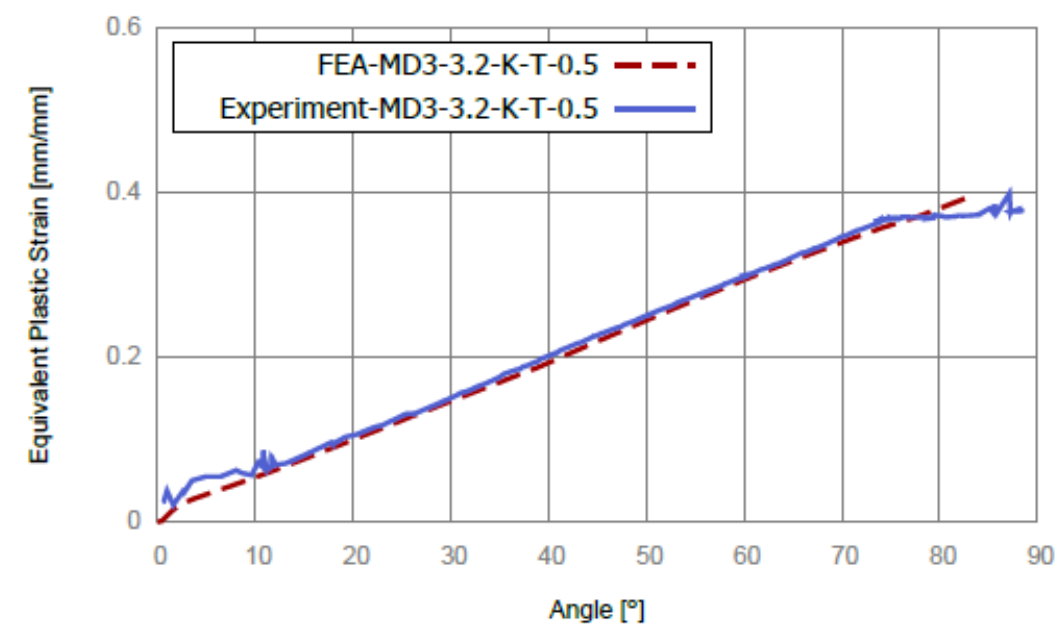

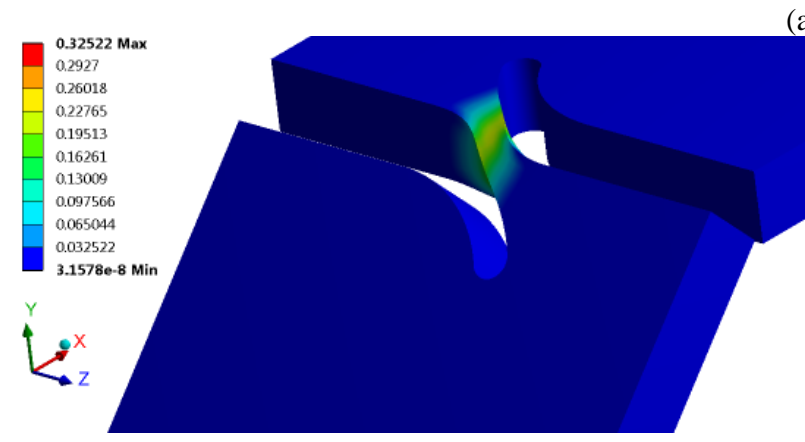

(b)

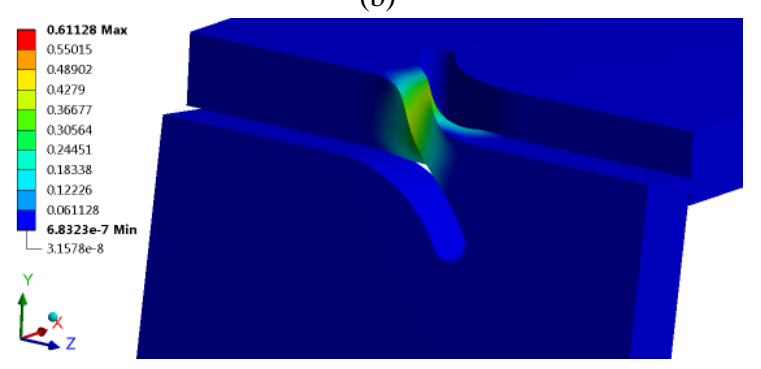

(d)

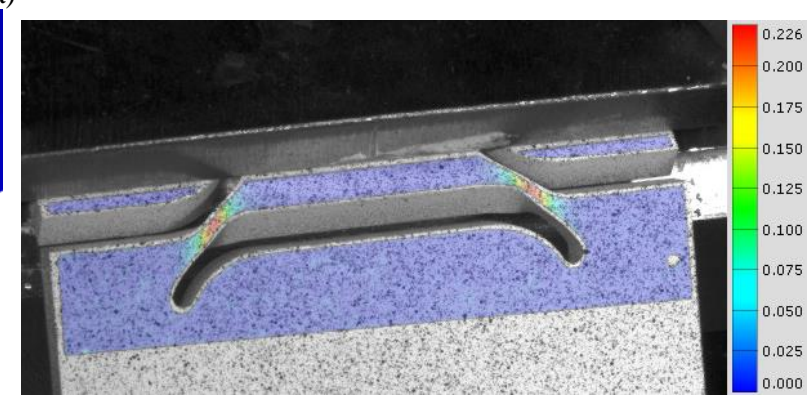

(c)

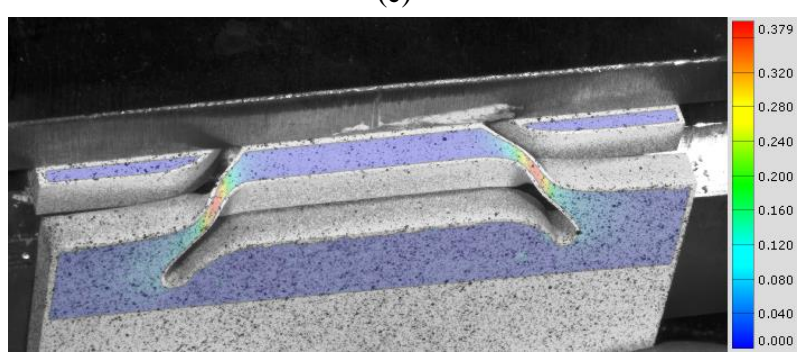

(e)

Figure 17 FEA validation for case No. 36 (MD-3-3.2-K-T-0.5). (a) equivalent plastic strain comparison between experiment and FEA; (b)FEA equivalent plastic strain field at $45^{\circ}$ bending; (c) experimental equivalent plastic strain field at $45^{\circ}$ bending;

(d) FEA equivalent plastic strain field at $90^{\circ}$ bending; (e) experimental equivalent plastic strain field at $90^{\circ}$ bending. 


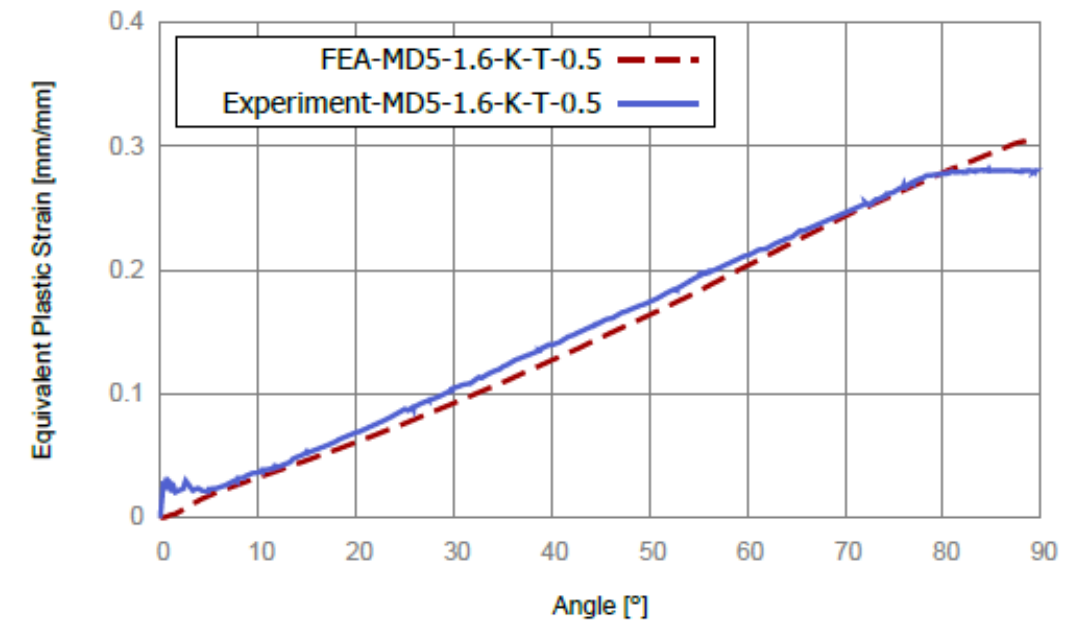

(a)

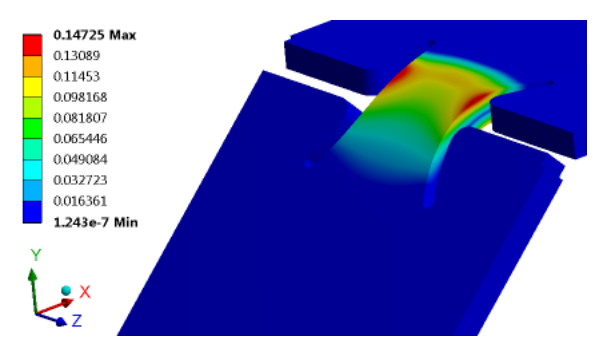

(b)
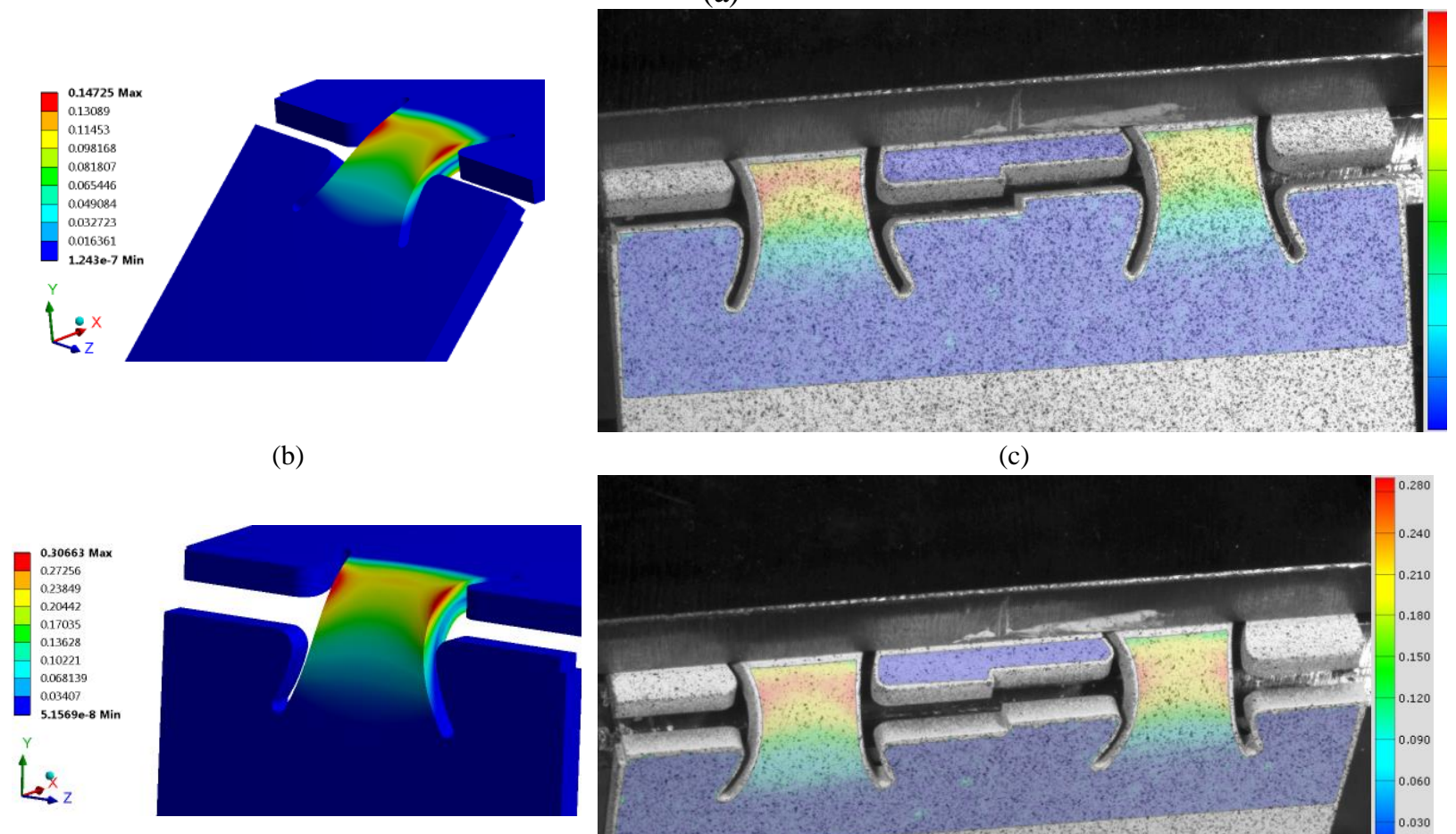

(d)

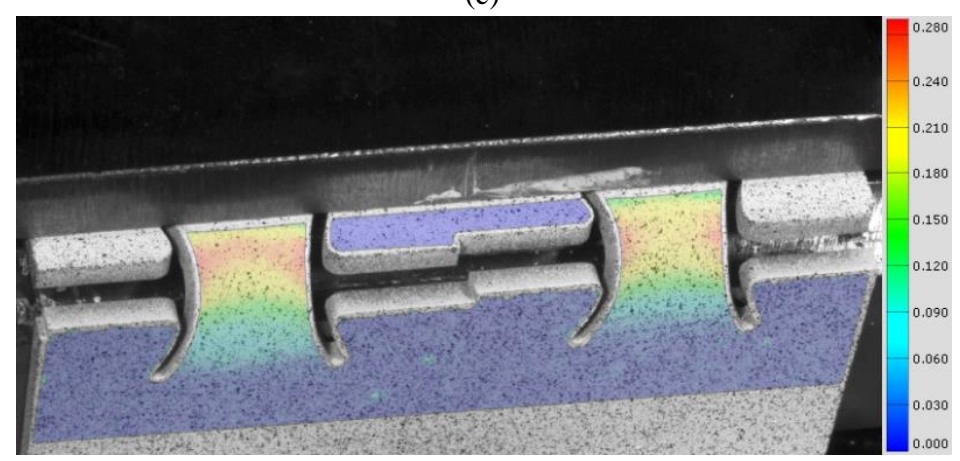

(e)

Figure 18 FEA validation for case No. 40 (MD-5-1.6-K-T-0.5). (a) equivalent plastic strain comparison between experiment and FEA; (b)FEA equivalent plastic strain field at $45^{\circ}$ bending; (c) experimental equivalent plastic strain field at $45^{\circ}$ bending;

(d) FEA equivalent plastic strain field at $90^{\circ}$ bending; (e) experimental equivalent plastic strain field at $90^{\circ}$ bending. 

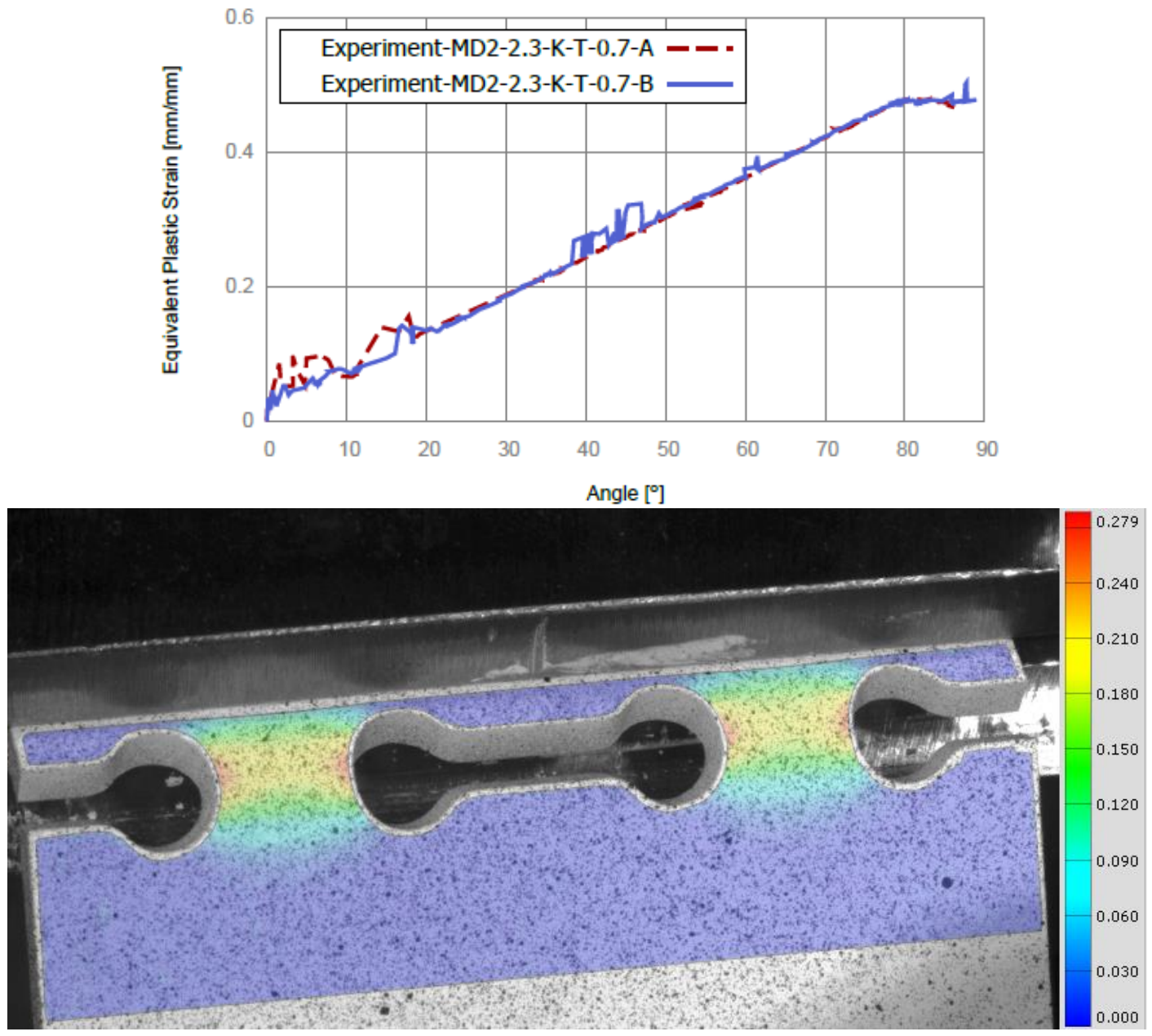

(b)

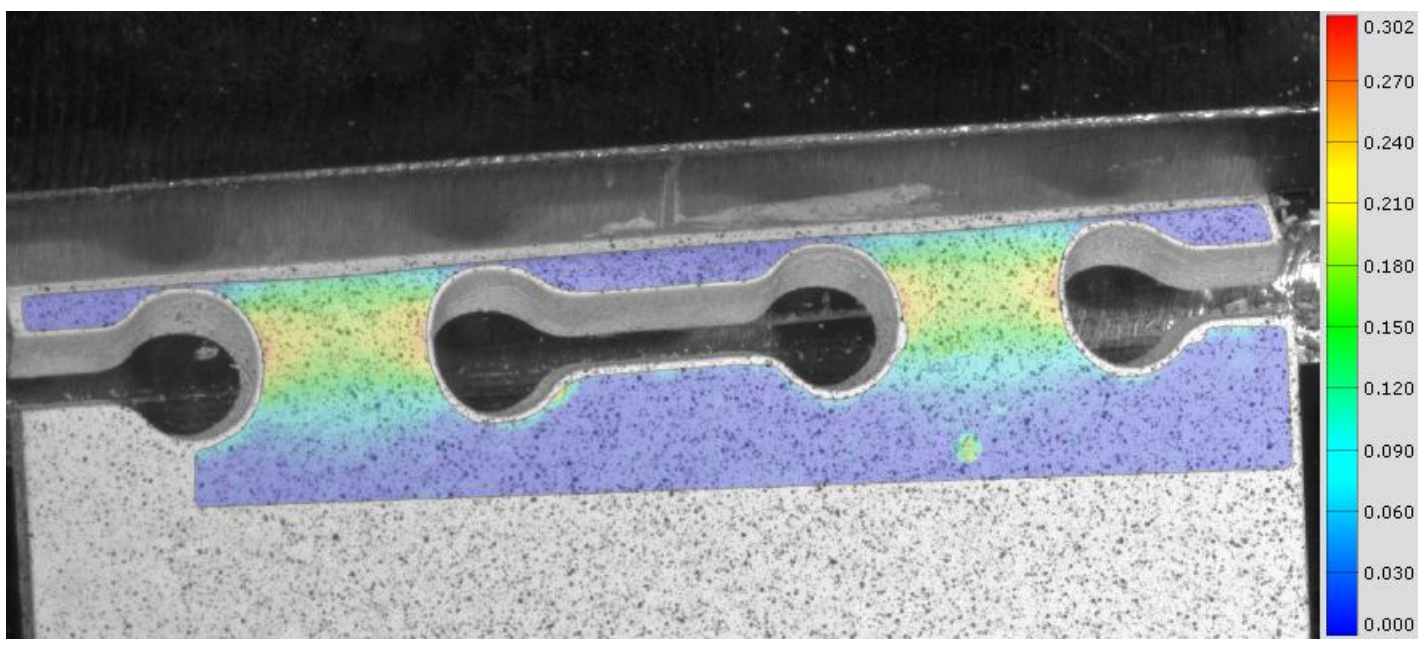

(c) 


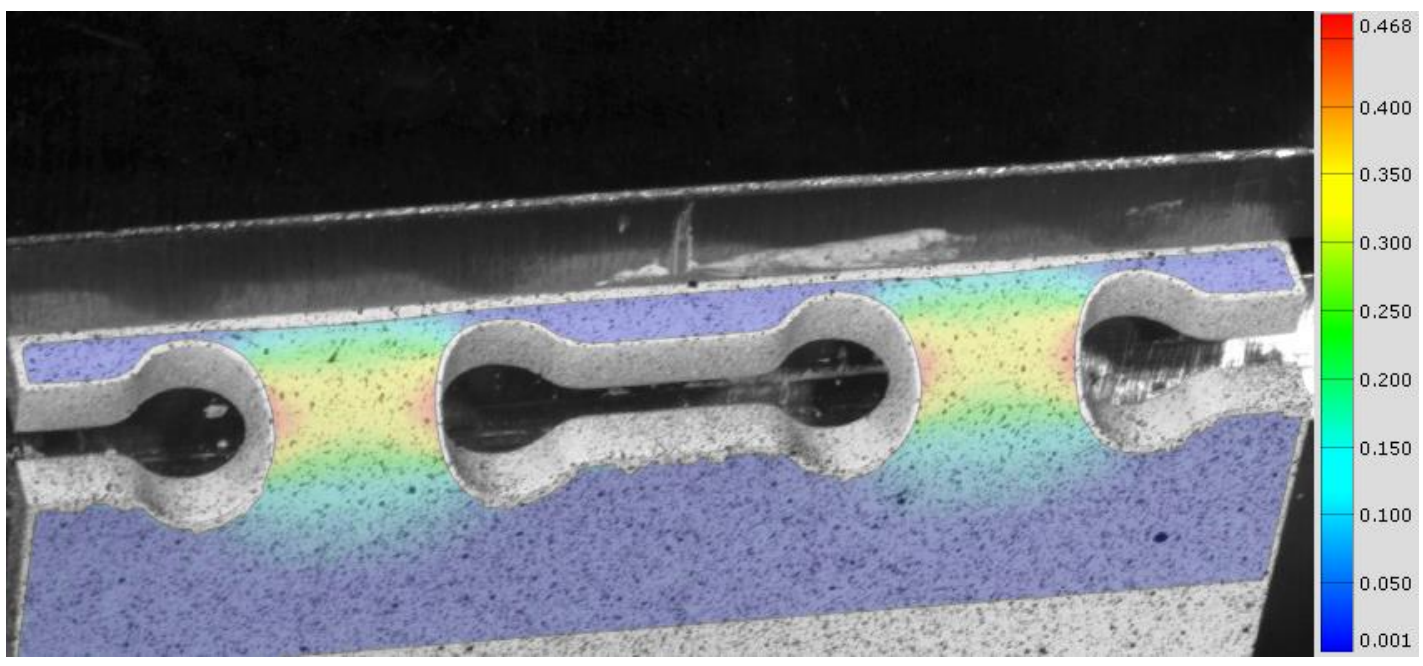

(d)

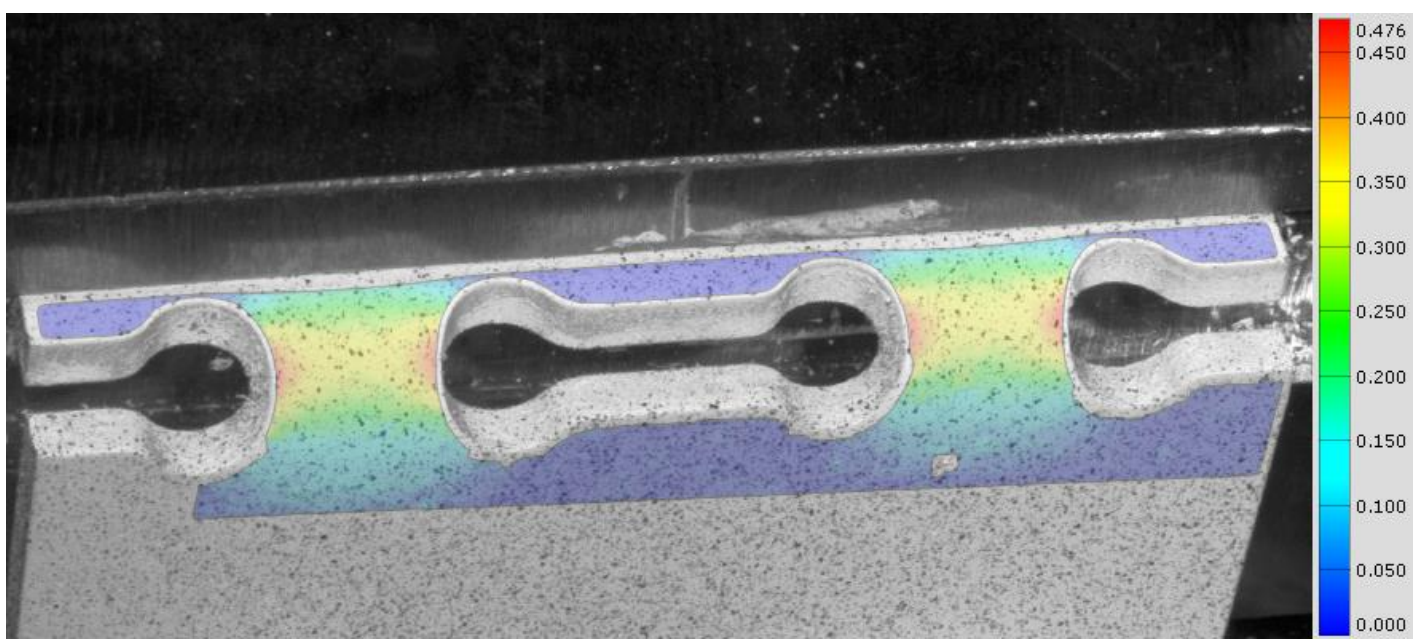

(e)

Figure 19 Repeatability of experiment case No. 18 (MD2-2.3-K-T-0.7). (a) equivalent plastic strain comparison between experiment run $\mathrm{A}$ and $\mathrm{B}$; equivalent plastic strain field (a) at $45^{\circ}$ bending from $\mathrm{A}$; (c) at $45^{\circ}$ bending from $\mathrm{B}$; (d) at $90^{\circ}$ bending from $\mathrm{A}$; (e) at $90^{\circ}$ bending from $\mathrm{B}$. 

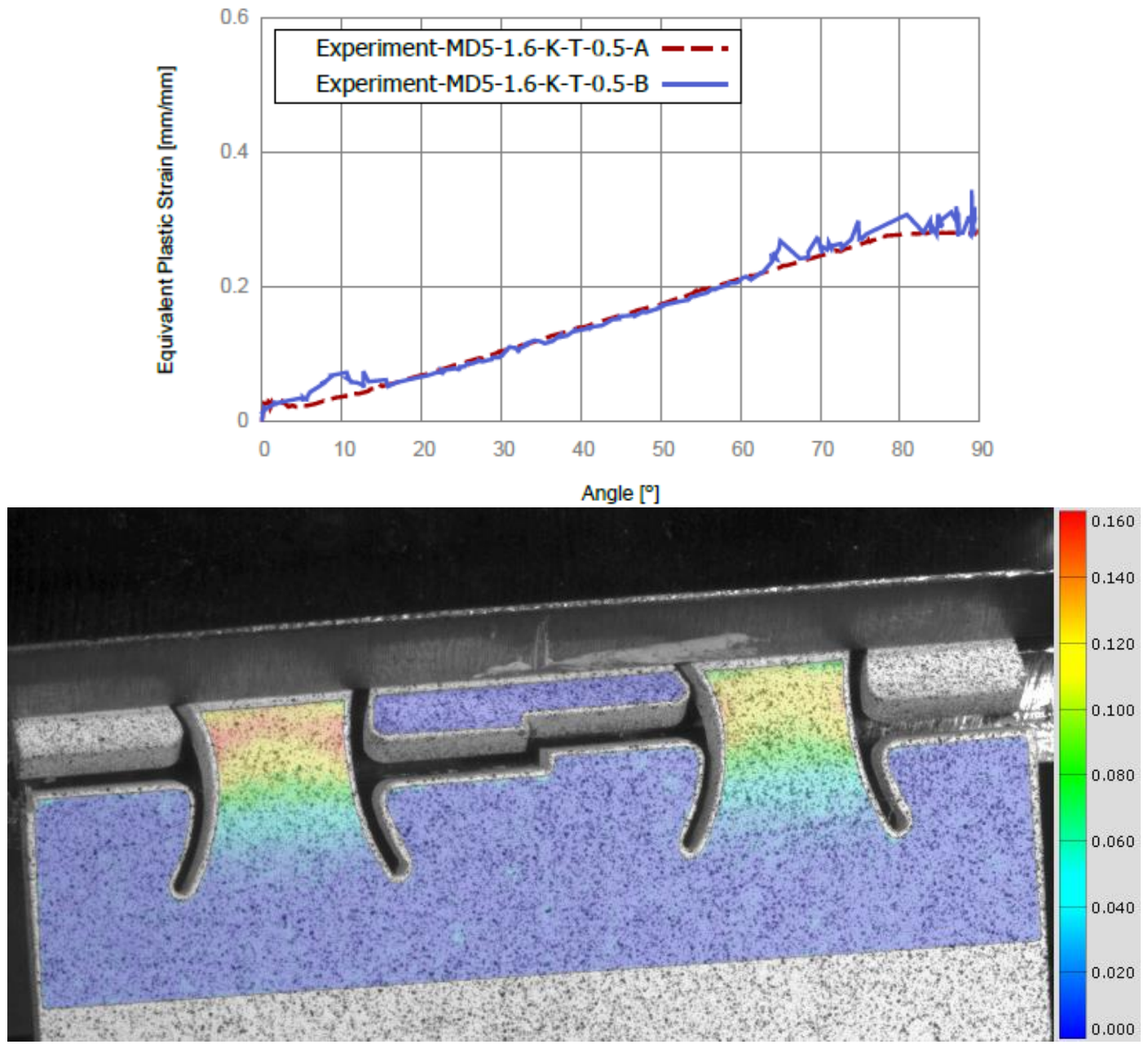

(b)

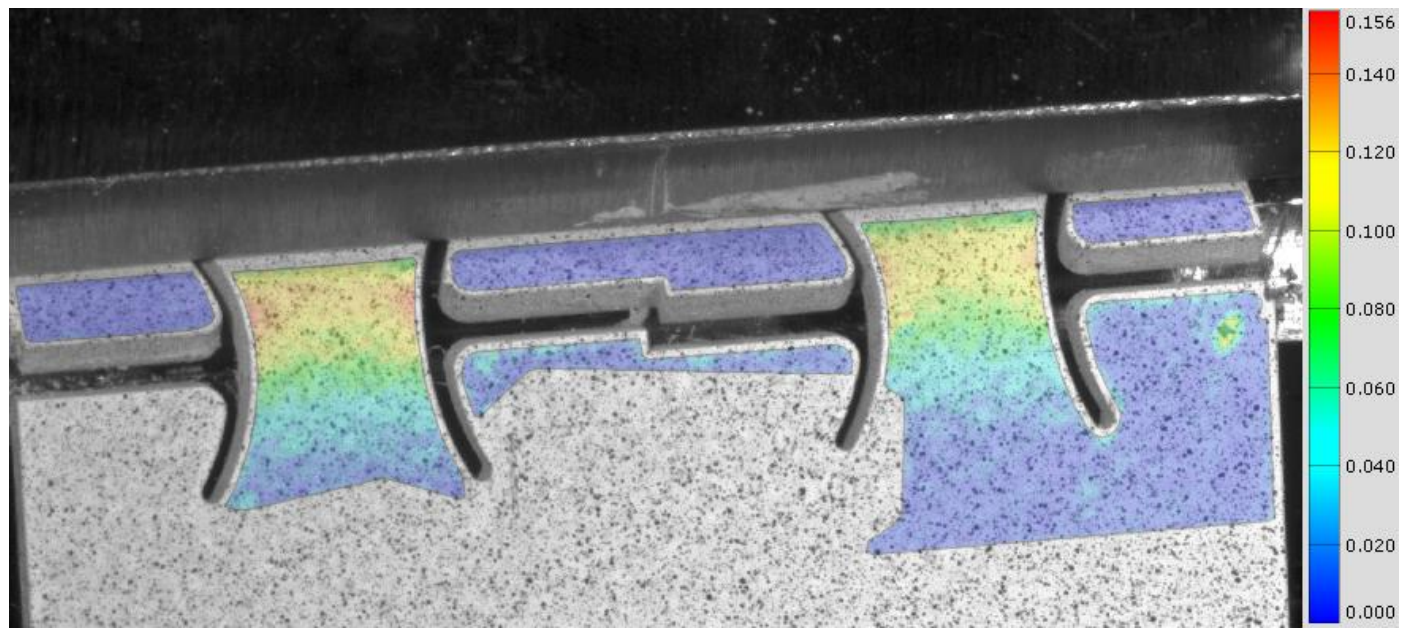

(c) 


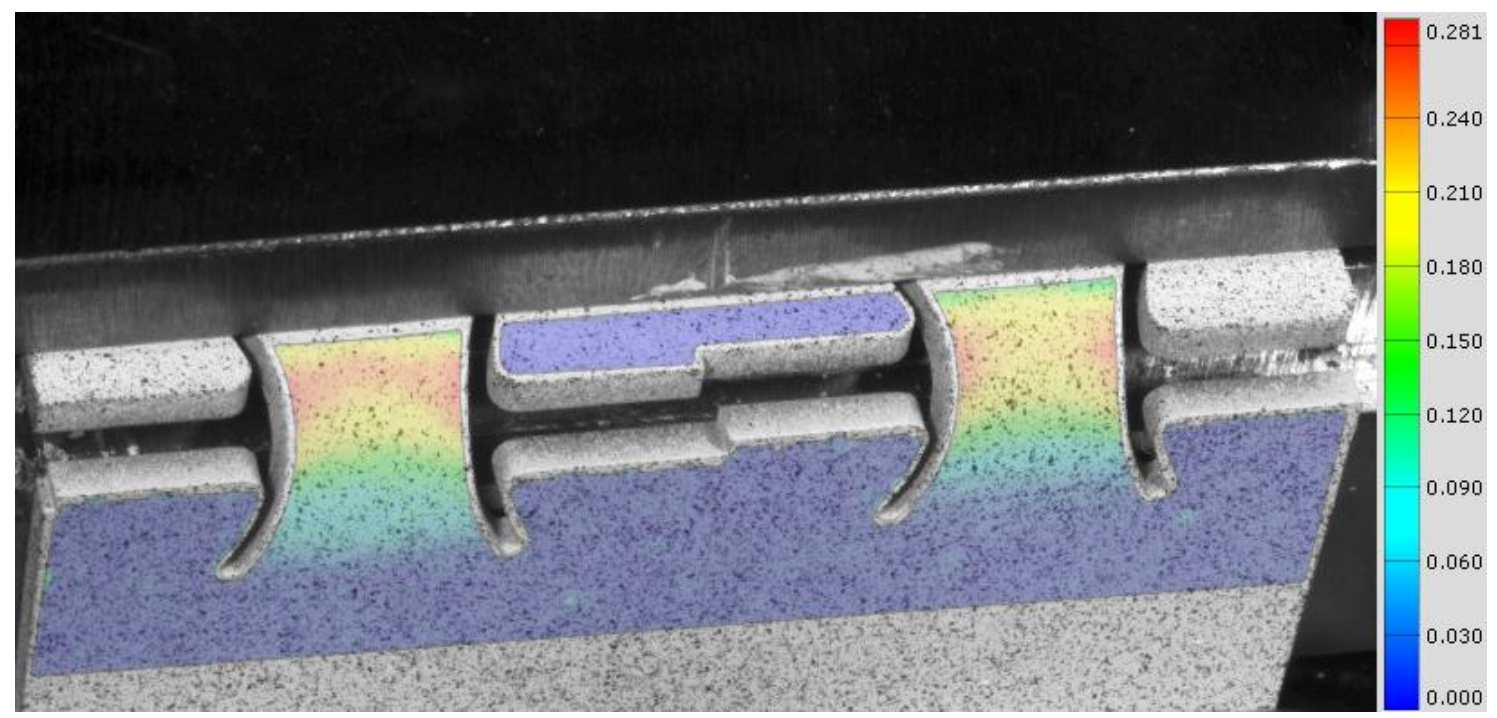

(d)

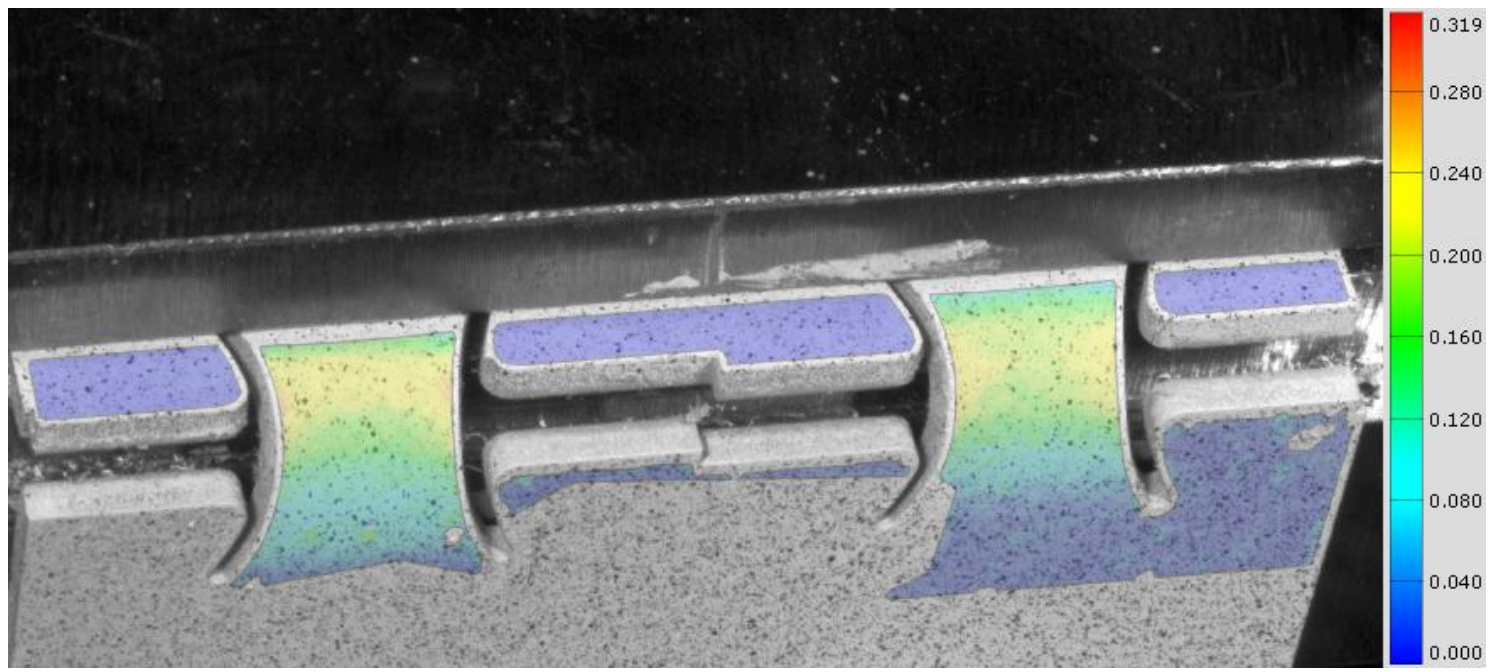

(e)

Figure 20 Repeatability of experiment case No. 40 (MD5-1.6-K-T-0.5). (a) equivalent plastic strain comparison between experiment run $\mathrm{A}$ and $\mathrm{B}$; equivalent plastic strain field (a) at $45^{\circ}$ bending from $\mathrm{A}$; (c) at $45^{\circ}$ bending from $\mathrm{B}$; (d) at $90^{\circ}$ bending from $\mathrm{A}$; (e) at $90^{\circ}$ bending from $\mathrm{B}$.

\section{Fracture Prediction in OSM bending}

The possibility of fracture occurring is evaluated from the OSM bending FEA. Related stress, strain fields are extracted, and DVs are calculated for all the cases following the same approach used to calculate CDVs for the tensile test. Table 3 lists the DVs for all 48 cases based on the selected four DFC. Fracture is predicted to occur when the DVs of an OSM bending case is equal to or greater than CDVs obtained from the tensile test. Bar charts in Figure 21 -

Figure 24 shows the prediction case by case. In the bar chart, a horizontal line representing the CDV based on the selected DFC is added to indicate the critical value, which aids in identifying the fracture cases conveniently.

Table 3 Case studies and damage values results

Case Thickness $\quad$ Damage Values




\begin{tabular}{|c|c|c|c|c|c|c|c|}
\hline No. & Name & {$[\mathrm{mm}]$} & $\begin{array}{c}\mathrm{K} / \mathrm{t} \\
\text { ratio }\end{array}$ & $\begin{array}{c}\text { Cockcroft- } \\
\text { Latham }\end{array}$ & Brozzo & Ayada & Rice-Tracy \\
\hline 1 & MD-1-1.6-k-t-0.3 & \multirow{5}{*}{1.6} & 0.3 & 1.3418 & 1.349 & 0.4898 & 2.2487 \\
\hline 2 & MD-1-1.6-k-t-0.5 & & 0.5 & 1.0483 & 1.054 & 0.3635 & 1.7472 \\
\hline 3 & MD-1-1.6-k-t-1 & & 1.0 & 0.7445 & 0.7484 & 0.2522 & 1.2326 \\
\hline 4 & MD-1-1.6-k-t-1.5 & & 1.5 & 0.6142 & 0.6174 & 0.2061 & 1.0145 \\
\hline 5 & MD-1-1.6-k-t-2 & & 2.0 & 0.537 & 0.5398 & 0.1795 & 0.8861 \\
\hline 6 & MD-1-2.3-k-t-0.3 & \multirow{5}{*}{2.3} & 0.3 & 1.3605 & 1.3676 & 0.486 & 2.2751 \\
\hline 7 & MD-1-2.3-k-t-0.5 & & 0.5 & 1.0763 & 1.0819 & 0.3685 & 1.7873 \\
\hline 8 & MD-1-2.3-k-t-1 & & 1.0 & 0.7775 & 0.7814 & 0.2608 & 1.284 \\
\hline 9 & MD-1-2.3-k-t-1.5 & & 1.5 & 0.6558 & 0.6592 & 0.2191 & 1.082 \\
\hline 10 & MD-1-2.3-k-t-2 & & 2.0 & 0.5909 & 0.5939 & 0.1971 & 0.9743 \\
\hline 11 & MD-1-3.2-k-t-0.3 & \multirow{5}{*}{3.2} & 0.3 & 1.3741 & 1.381 & 0.4804 & 2.2802 \\
\hline 12 & MD-1-3.2-k-t-0.5 & & 0.5 & 1.1251 & 1.1308 & 0.3829 & 1.8651 \\
\hline 13 & MD-1-3.2-k-t-1 & & 1.0 & 0.8376 & 0.8418 & 0.2801 & 1.3821 \\
\hline 14 & MD-1-3.2-k-t-1.5 & & 1.5 & 0.7251 & 0.7287 & 0.2416 & 1.1953 \\
\hline 15 & MD-1-3.2-k-t-2 & & 2.0 & 0.6416 & 0.6448 & 0.2134 & 1.0573 \\
\hline 16 & MD-2-1.6-k-t-0.3 & \multirow{3}{*}{1.6} & 0.3 & 0.7987 & 0.803 & 0.272 & 1.3244 \\
\hline 17 & MD-2-1.6-k-t-0.5 & & 0.5 & 0.6282 & 0.6315 & 0.2115 & 1.0385 \\
\hline 18 & MD-2-1.6-k-t-0.7 & & 0.7 & 0.5405 & 0.5433 & 0.1813 & 0.8926 \\
\hline 19 & MD-2-2.3-k-t-0.3 & \multirow{3}{*}{2.3} & 0.3 & 0.8169 & 0.8211 & 0.2667 & 1.3526 \\
\hline 20 & MD-2-2.3-k-t-0.5 & & 0.5 & 0.661 & 0.6644 & 0.2217 & 1.0917 \\
\hline 21 & MD-2-2.3-k-t-0.7 & & 0.7 & 0.5794 & 0.5823 & 0.1936 & 0.9559 \\
\hline 22 & MD-2-3.2-k-t-0.3 & \multirow{3}{*}{3.2} & 0.3 & 0.8656 & 0.8701 & 0.2936 & 1.4337 \\
\hline 23 & MD-2-3.2-k-t-0.5 & & 0.5 & 0.7143 & 0.718 & 0.2401 & 1.1804 \\
\hline 24 & MD-2-3.2-k-t-0.7 & & 0.7 & 0.6444 & 0.6477 & 0.2209 & 1.063 \\
\hline 25 & MD-3-1.6-k-t-0.2 & \multirow{4}{*}{1.6} & 0.2 & 0.2304 & 0.2316 & 0.0744 & 0.377 \\
\hline 26 & MD-3-1.6-k-t-0.3 & & 0.3 & 0.2313 & 0.2325 & 0.075 & 0.3789 \\
\hline 27 & MD-3-1.6-k-t-0.4 & & 0.4 & 0.2534 & 0.2548 & 0.0809 & 0.414 \\
\hline 28 & MD-3-1.6-k-t-0.5 & & 0.5 & 0.2475 & 0.2489 & 0.078 & 0.403 \\
\hline 29 & MD-3-2.3-k-t-0.2 & \multirow{4}{*}{2.3} & 0.2 & 0.3443 & 0.3461 & 0.1127 & 0.5652 \\
\hline 30 & MD-3-2.3-k-t-0.3 & & 0.3 & 0.3407 & 0.3424 & 0.1109 & 0.5585 \\
\hline 31 & MD-3-2.3-k-t-0.4 & & 0.4 & 0.2886 & 0.2901 & 0.0935 & 0.4726 \\
\hline 32 & MD-3-2.3-k-t-0.5 & & 0.5 & 0.3223 & 0.324 & 0.1043 & 0.5277 \\
\hline 33 & MD-3-3.2-k-t-0.2 & \multirow{4}{*}{3.2} & 0.2 & 0.4736 & 0.476 & 0.1566 & 0.78 \\
\hline 34 & MD-3-3.2-k-t-0.3 & & 0.3 & 0.4649 & 0.4673 & 0.1533 & 0.7645 \\
\hline 35 & MD-3-3.2-k-t-0.4 & & 0.4 & 0.4231 & 0.4252 & 0.1389 & 0.695 \\
\hline 36 & MD-3-3.2-k-t-0.5 & & 0.5 & 0.3948 & 0.3968 & 0.1291 & 0.648 \\
\hline 37 & MD-5-1.6-k-t-0.2 & \multirow{4}{*}{1.6} & 0.2 & 0.3029 & 0.3044 & 0.1276 & 0.5291 \\
\hline 38 & MD-5-1.6-k-t-0.3 & & 0.3 & 0.3034 & 0.305 & 0.127 & 0.5265 \\
\hline 39 & MD-5-1.6-k-t-0.4 & & 0.4 & 0.3044 & 0.3059 & 0.1265 & 0.5251 \\
\hline 40 & MD-5-1.6-k-t-0.5 & & 0.5 & 0.3035 & 0.305 & 0.1272 & 0.5272 \\
\hline 41 & MD-5-2.3-k-t-0.2 & \multirow{3}{*}{2.3} & 0.2 & 0.3911 & 0.3931 & 0.1621 & 0.676 \\
\hline 42 & MD-5-2.3-k-t-0.33.2 & & 0.3 & 0.3914 & 0.3933 & 0.1623 & 0.6772 \\
\hline 43 & MD-5-2.3-k-t-0.4 & & 0.4 & 0.3928 & 0.3948 & 0.162 & 0.6762 \\
\hline
\end{tabular}




\begin{tabular}{|c|c|c|c|c|c|c|c|}
\hline 44 & MD-5-2.3-k-t-0.5 & & 0.5 & 0.3941 & 0.3961 & 0.1638 & 0.6835 \\
\hline 45 & MD-5-3.2-k-t- 0.2 & \multirow{4}{*}{3.2} & 0.2 & 0.4883 & 0.4908 & 0.2002 & 0.8439 \\
\hline 46 & MD-5-3.2-k-t- 0.3 & & 0.3 & 0.4884 & 0.4908 & 0.1997 & 0.8428 \\
\hline 47 & MD-5-3.2-k-t- 0.4 & & 0.4 & 0.4885 & 0.491 & 0.2 & 0.8431 \\
\hline 48 & MD-5-3.2-k-t-0.5 & & 0.5 & 0.4892 & 0.4916 & 0.2004 & 0.846 \\
\hline
\end{tabular}

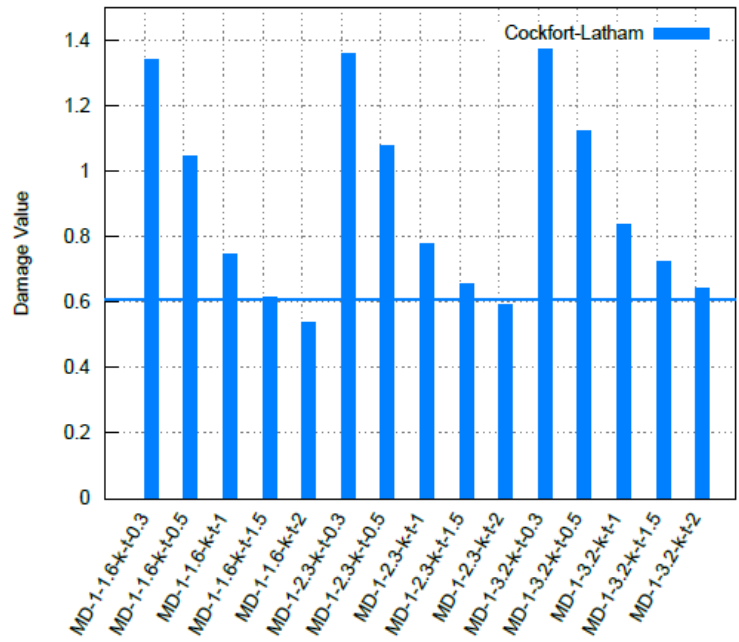

(a)

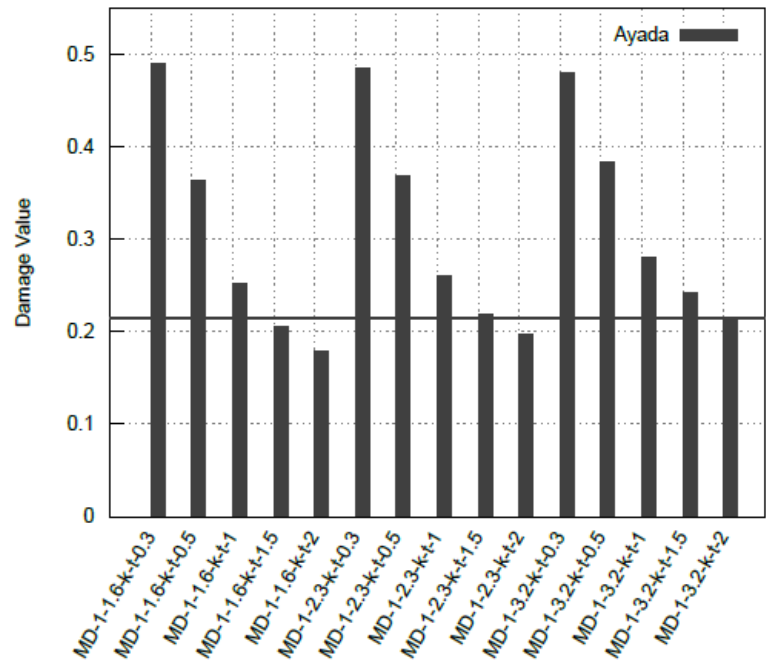

(c)

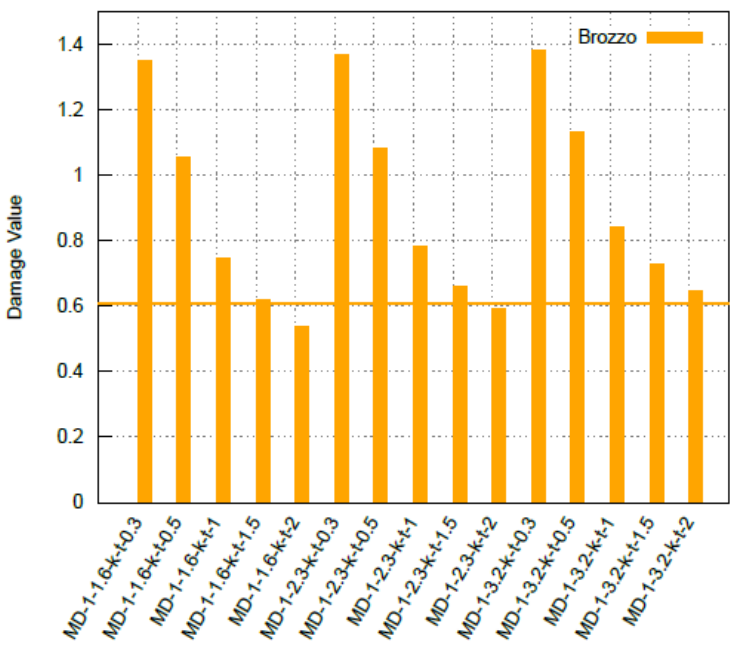

(b)

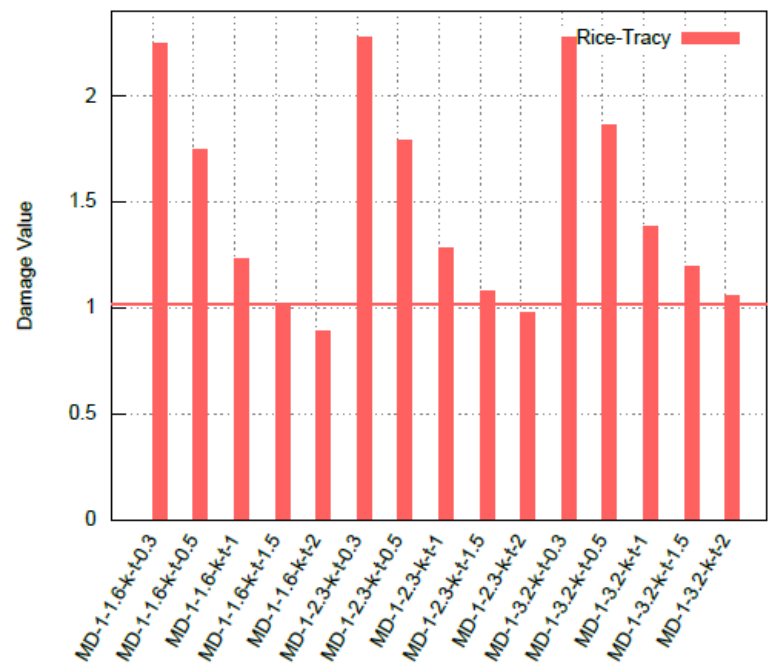

(d)

Figure 21 Fracture prediction for MD-1 cases according to (a) Cockcroft-Latham criterion; (b) Brozzo criterion; (c) Ayada criterion; (d) Rice-Tracy criterion. 

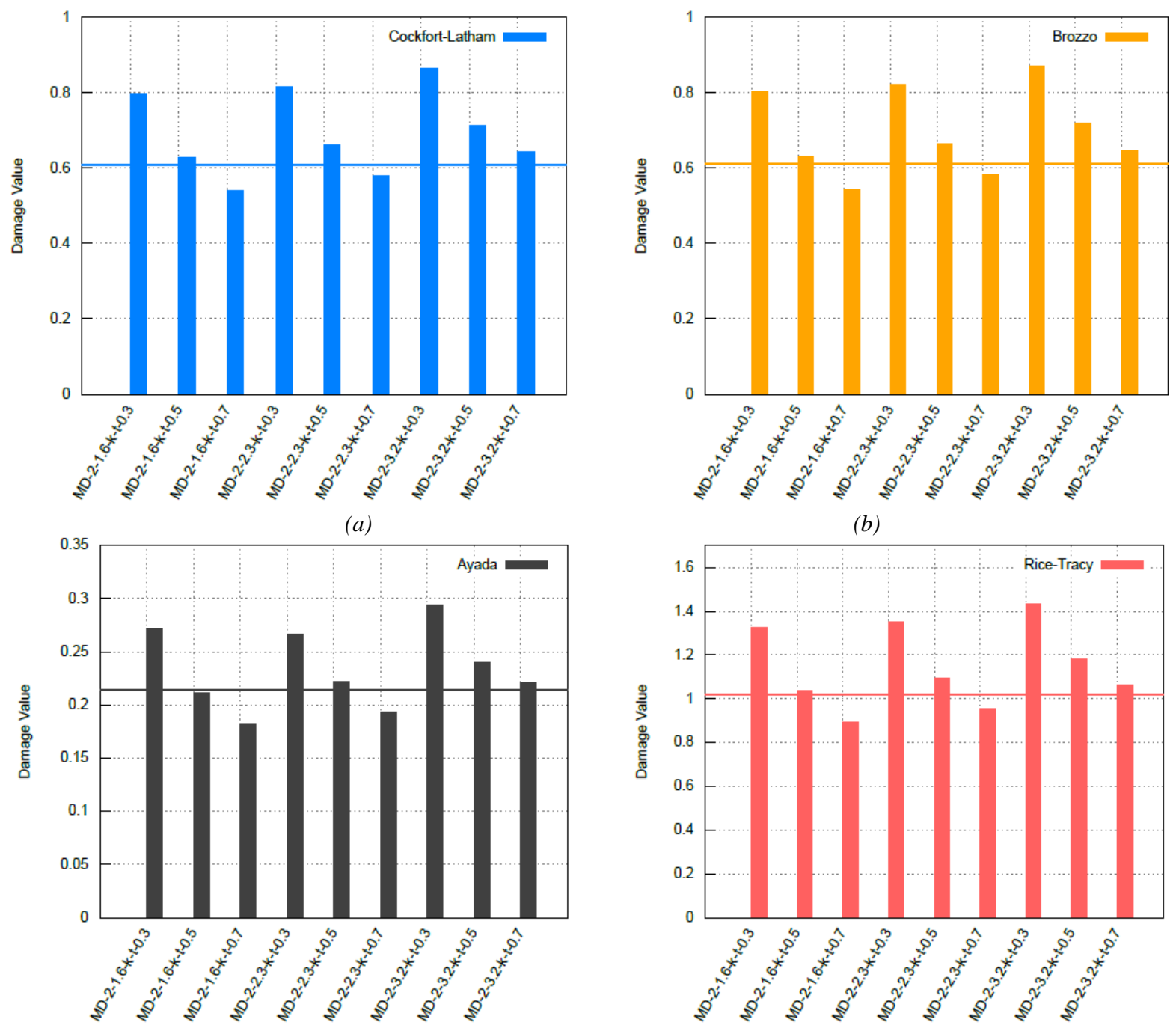

(c)

(d)

Figure 22 Fracture prediction on MD-2 according to (a) Cockcroft-Latham criterion; (b) Brozzo criterion; (c) Ayada criterion; (d) Rice-Tracy criterion. 

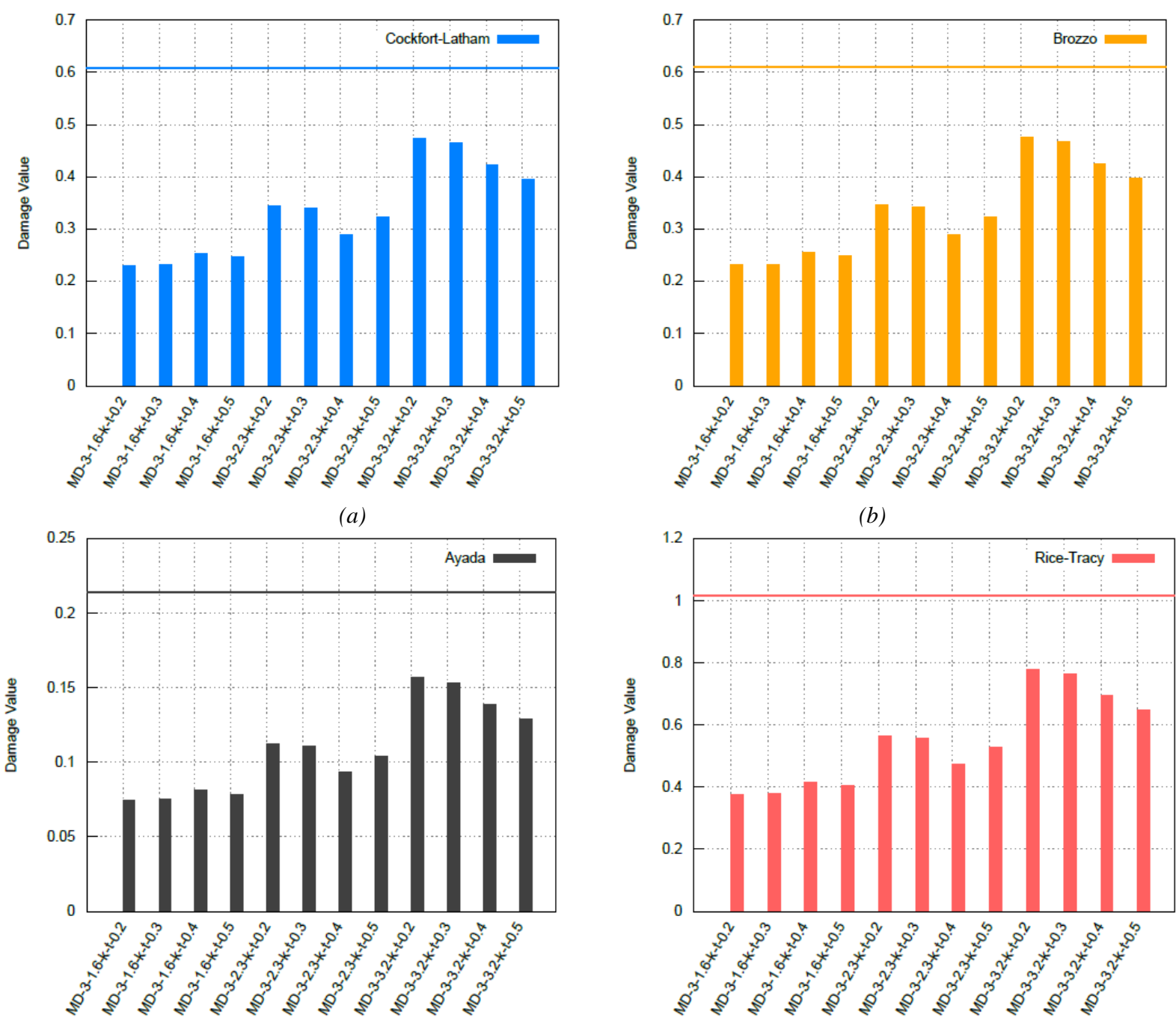

(c)

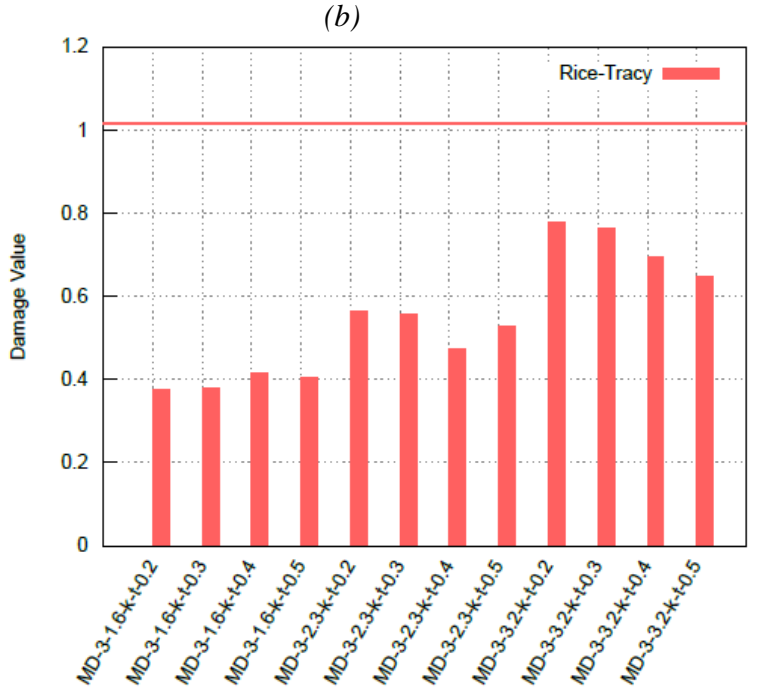

(d)

Figure 23 Fracture prediction on MD-3 according to (a) Cockcroft-Latham criterion; (b) Brozzo criterion; (c) Ayada criterion; (d) Rice-Tracy criterion. 


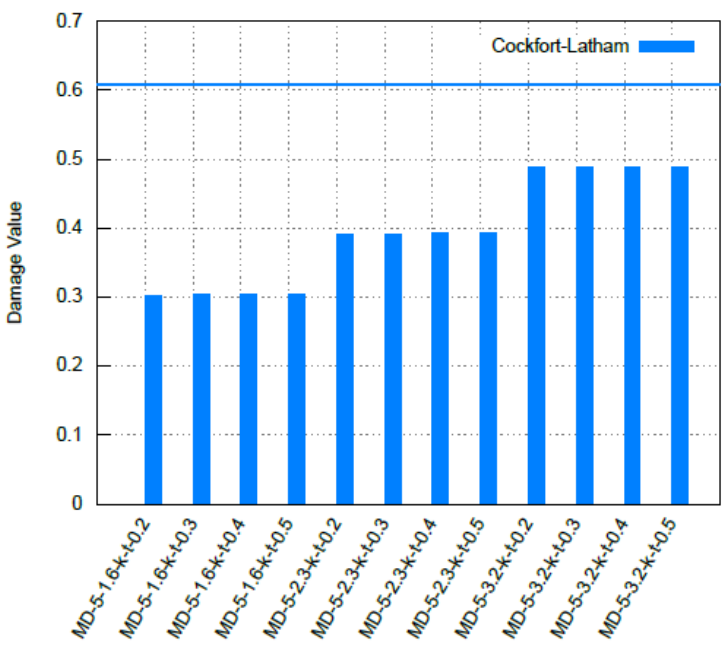

(a)

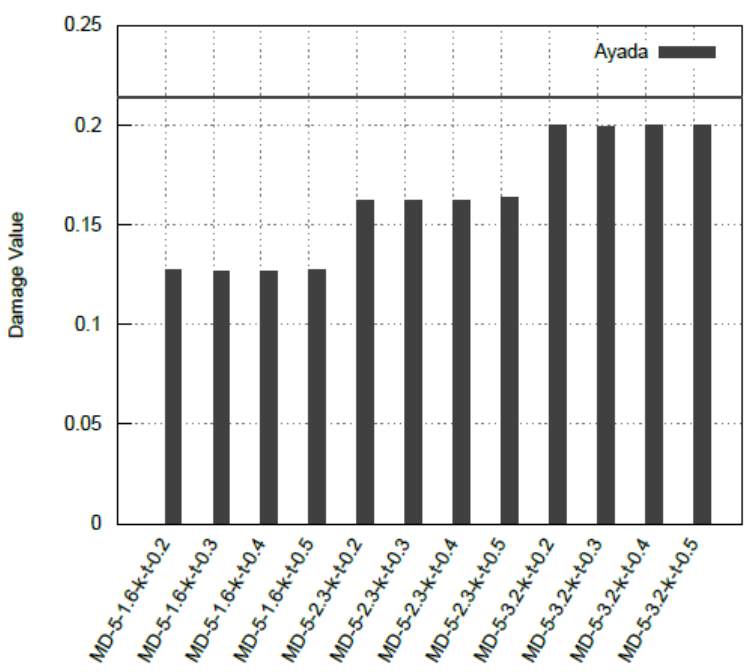

(c)

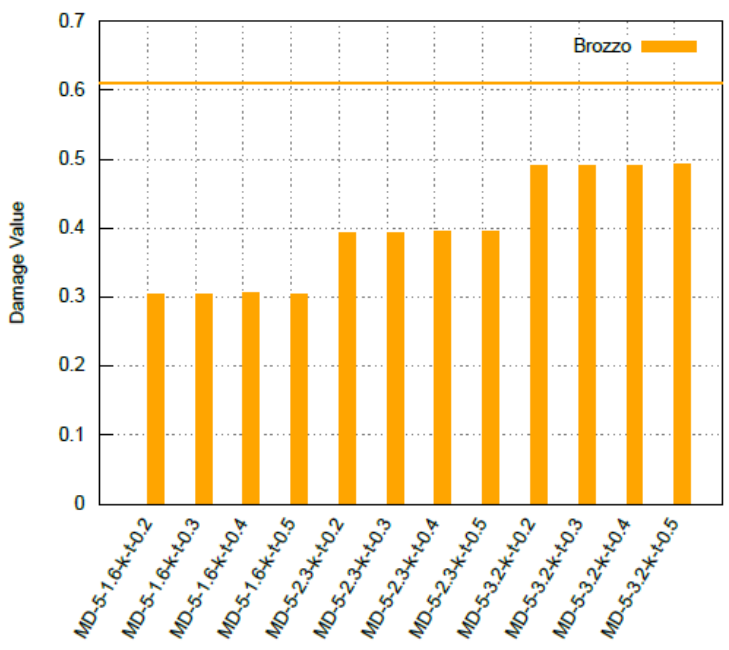

(b)

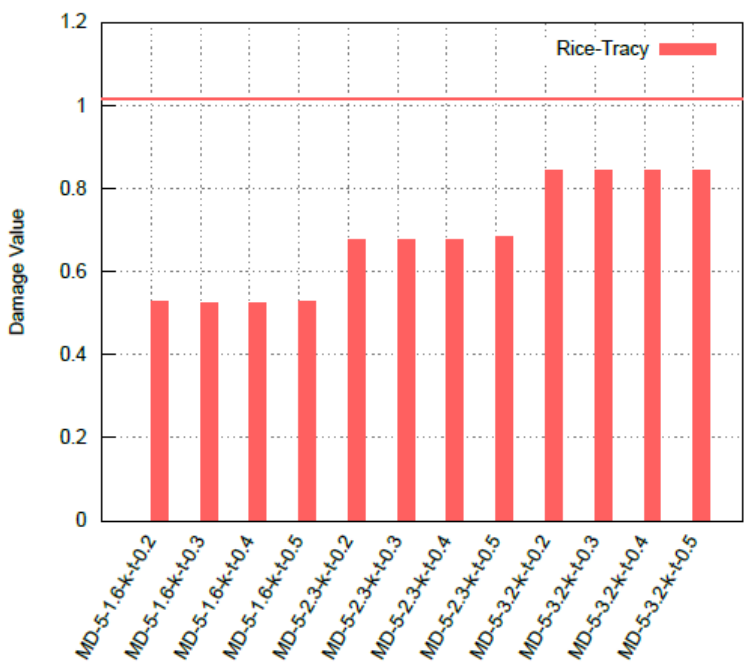

(d)

Figure 24 Fracture prediction on MD-5 according to (a) Cockcroft-Latham criterion; (b) Brozzo criterion; (c) Ayada criterion; (d) Rice-Tracy criterion.

\subsection{Effect of $\mathrm{k} / \mathrm{t}$ ratio}

Different numbers of $\mathrm{k} / \mathrm{t}$ ratios are evaluated for each type of MD. The results exhibited two different trends. The first trend is that the larger the $\mathrm{k} / \mathrm{t}$ ratio is, the less likely a fracture occurs. This can be seen from the predictions for MD-1 and MD-2 shown in Figure 21 and

Figure 22. All four DFC followed the same pattern to $\mathrm{k} / \mathrm{t}$ ratio. It is seen that the increase of the $\mathrm{k} / \mathrm{t}$ ratio results in a drop in the DVs, and gradually the DVs go under the safe zone below the CDVs. The second trend is exhibited on MD3 and MD-5 as shown in Figure 23 and

Figure 24, where the DVs stay constant regardless of changes in the $\mathrm{k} / \mathrm{t}$ ratio. Even though there is some fluctuation on MD-3, it is not as large as the fluctuation observed on MD-1 and MD-2.

The reason for the two different trends is related to the curvature radius of the MDs, as shown in 
Figure 25. On MD-1 and MD-2, the curvature radius is significantly smaller than that of MD-3 and MD-5. A small curvature radius causes high-stress concentration leading to fracture. Hence, a change in the $\mathrm{k} / \mathrm{t}$ ratio of MD-1, and MD-2 generate a large shift in DVs, whereas, in MD-3 and MD-5, the k/t ratio doesn't result in a change of DVs.

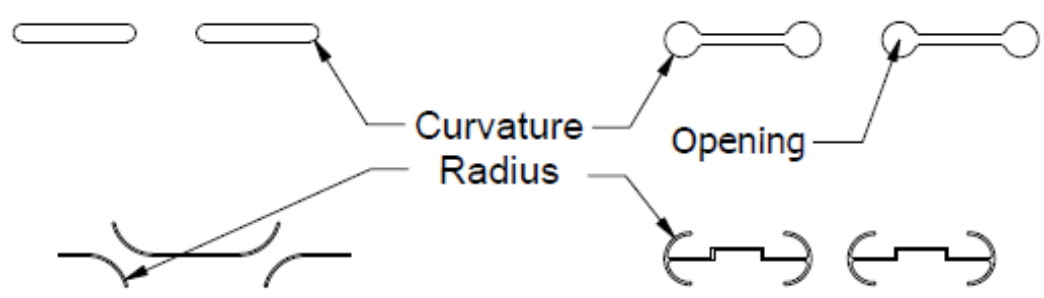

Figure 25 Curvature radius and opening in MDs

The results also yield the limit $\mathrm{k} / \mathrm{t}$ ratio for the MDs, beyond which a fracture can occur. For sheets with an $\mathrm{MD}-1$, a $\mathrm{k} / \mathrm{t}$ ratio of 2 is the limit $\mathrm{k} / \mathrm{t}$ ratio when the thickness is less than $2.3 \mathrm{~mm}$ because a fracture is predicted when the thickness is 3.2. For a sheet with MD-2, a k/t ratio of 0.7 is the safe $k / t$ ratio when the thickness is equal to or less than $2.3 \mathrm{~mm}$. The reason MD-2 can tolerate a much smaller $\mathrm{k} / \mathrm{t}$ ratio is due to the opening at the end of the MD-2.

For MD-3 and MD-5, all k/t ratios investigated don't give rise to a fracture regardless of the thickness. MD3 and MD-5 can be applied with a k/t ratio as small as 0.2. These two MDs are good choices for small k/t ratios.

\subsection{Effect of sheet thickness}

The thicker the sheet thickness, the more likely a fracture happens during the OSM bending. This trend is evident regardless of the MD type investigated in this study. This can be explained by the fact that the DVs are defined as plastic work done to the sheet. The thicker the sheet, the more work it requires to be bent to the same angle. This indicates that a smaller $\mathrm{k} / \mathrm{t}$ ratio can be combined with a thinner thickness to obtain a balanced choice for the design.

\section{Conclusion}

This work carried out a quantitative investigation on the possibility of fracture during OSM bending due to different MD k/t ratios, sheet thicknesses, and MD types. The fracture possibility is predicted using four different DFC to determine proper MD k/t ratios for the investigated MD types.

The study results reveal that:

- a higher ratio of kerf to the thickness of the sheet (i.e. referred to as $\mathrm{k} / \mathrm{t}$ ratio) reduces the possibility of MD fracture because a small $\mathrm{k} / \mathrm{t}$ ratio is associated with a higher stress concentration on MDs.

- the MDs are more likely to fracture on a thicker sheet than it does on a thinner sheet.

- the investigation also provided a safe $\mathrm{k} / \mathrm{t}$ ratio for the MD studied in this work. For MD1, the safe $\mathrm{k} / \mathrm{t}$ ratio is 2 , and the safe $\mathrm{k} / \mathrm{t}$ ratios for MD-2, MD-3, and MD-5 are 0.7, 0.2, and 0.2, respectively.

- the fracture possibility is influenced by the topology of the MDs. 
- for some MD types such as MD-1 and MD-2, there is a limiting $\mathrm{k} / \mathrm{t}$ ratio that induces a fracture, while no fracture occurs for other MD types such as MD-3 and MD-5 even with very small k/t ratios due to their unique topology.

The investigation can be extended to different types of materials, MDs, and thicknesses to cover various design requirements. It can also be expanded to identify a topology that can resist fracture more efficiently.

Nomenclature

\begin{tabular}{ll}
\hline $2-\mathrm{D}$ & Two-dimensional \\
$3-\mathrm{D}$ & Three-dimensional \\
$\mathrm{CDV}$ & Critical damage value \\
$\mathrm{D}_{\mathrm{i}}(\mathrm{i}=1,2,3,4)$ & Damage values corresponding to each of these DFC \\
$\mathrm{DFC}$ & Ductile fracture criteria \\
$\mathrm{DV}$ & Damage value \\
$\bar{\varepsilon}_{\mathrm{p}}$ & Equivalent plastic strain \\
$\bar{\varepsilon}_{\mathrm{p}}^{\mathrm{f}}$ & Equivalent plastic strain at fracture \\
$\epsilon$ & True strain \\
$\epsilon_{u}$ & Ultimate true strain \\
$\mathrm{FFLD}$ & Fracture forming limit diagram \\
$\mathrm{FEA}$ & Finite element analysis \\
$\mathrm{FLD}$ & Forming limit diagrams \\
$\mathrm{g}$ & Punch placement \\
$\mathrm{k} / \mathrm{t}$ ratio & Kerf-to-thickness ratio \\
$\mathrm{MD}$ & Material discontinuity \\
$\mathrm{OSM}$ & Origami-based sheet metal \\
$\mathrm{Rp}$ & Punch radius \\
$\mathrm{s}$ & Offset distance \\
$\sigma$ & True stress \\
$\sigma_{i}(i=1,2,3)$ & Principal stresses \\
$\sigma_{e q}$ & Equivalent stress \\
$\sigma_{h}$ & Hydrostatic stress \\
$\sigma_{u}$ & Ultimate true stress \\
$\mathrm{w}$ & Weight factor \\
\hline
\end{tabular}

\section{Declarations}

Funding: This work was partially supported by Hellman Fellow Fund.

Conflict of interest/Competing interests The authors declare no conflict of interest

Availability of data and material

Code availability

References

1. Turner N, Goodwine B, Sen M (2015) A review of origami and its applications in mechanical engineering. J Mech Eng Sci 0:1-18. https://doi.org/10.1177/0954406215597713

2. Lang RJ, Tolman K, Crampton E, et al (2018) Accommodating thickness in origami-inspired engineered systems. Appl Mech Rev 70:1-20. https://doi.org/10.1115/1.4039314 
3. Edmondson BJ, Lang RJ, Howell LL (2014) An offset panel technique for thick rigidly foldable origami. In: ASME 2014 International Design Engineering Technical Conferences and Computers and Information in Engineering Conference, IDETC/CIE 2014. New York, USA, pp 1-8

4. Crampton EB, Magleby SP, Howell LL (2017) Realizing origami mechanism from metal sheets. In: The ASME 2017 International Design Engineering Technical Conferences and Computers and Information in Engineering Conference IDETC/CIE 2017. Cleveland, USA, pp 1-10

5. Wu W, You Z (2011) A solution for folding rigid tall shopping bags. Proc R Soc A Math Phys Eng Sci 467:2561-2574. https://doi.org/10.1098/rspa.2011.0120

6. Durney MW, Pendley AD, Rappaport IS (2006) Techniques for designing and manufacturing precision-folded, high strength, fatigue-resistant structures and sheet therefor. 1-64

7. Ablat MA, Qattawi A (2018) Finite element analysis of origami-based sheet metal folding process. J Eng Mater Technol 140:031008. https://doi.org/doi:10.1115/1.4039505

8. Ablat MA, Qattawi A (2019) Investigating the design and process parameters of folded perforated sheet metal. Int J Adv Manuf Technol. https://doi.org/10.1007/s00170-018-3149-5

9. Ablat MA, Qattawi A, Jaman MS, et al (2020) An experimental and analytical model for force prediction in sheet metal forming process using perforated sheet and origami principles. Procedia Manuf 48:407-418. https://doi.org/10.1016/j.promfg.2020.05.063

10. Kuo CC, Li MR (2016) A cost-effective method for rapid manufacturing sheet metal forming dies. Int J Adv Manuf Technol 85:2651-2656. https://doi.org/10.1007/s00170-015-8139-2

11. Qattawi A (2012) Extending origami technique to fold forming of sheet metal. Ph.D. Dissertation. Clemson University

12. Qattawi A, Mayyas A, Thiruvengadam H, et al (2014) Design considerations of flat patterns analysis techniques when applied for folding 3-D sheet metal geometries. J Intell Manuf 25:109128. https://doi.org/10.1007/s10845-012-0679-9

13. Qattawi A, Abdelhamid M, Mayyas A, Omar M (2014) Design analysis for origami-based folded sheet metal parts. SAE Int J Mater Manuf 7:488-498. https://doi.org/10.4271/2014-01-9098

14. Venhovens P, Bell K, Marathe P, et al (2013) Application of a novel metal folding technology for automotive BiW design. SAE Int J Passeng Cars - Mech Syst 6:584-600. https://doi.org/10.4271/2013-01-0373

15. Shi Q, Shi X, Gattas JM, Kitipornchai S (2017) Folded assembly methods for thin-walled steel structures. J Constr Steel Res 138:235-245. https://doi.org/10.1016/j.jcsr.2017.07.010

16. Shi Q, Heitzmann MT, Gattas JM (2020) Nonlinear rotational stiffness and clash prevention in perforated steel fold lines. Eng Struct 209:110218

17. Nikhare CP (2019) Bending and springback analysis on sheet metal material discontinuity. In: ASME 2019 14th International Manufacturing Science and Engineering Conference, MSEC 2019. pp 1-7

18. Emmens WC (2011) Formability: a review of parameters and processes that control, limit, or enhance the formability of sheet metal. Springer Heidelberg Dordrecht London New York

19. Hajian M, Assempour A (2014) Experimental and numerical determination of forming limit diagram for 1010 steel sheet: a crystal plasticity approach. Int J Adv Manuf Technol 76:17571767. https://doi.org/10.1007/s00170-014-6339-9

20. Zhang R, Shao Z, Shi Z, et al (2021) Effect of cruciform specimen design on strain paths and fracture location in equi-biaxial tension. J Mater Process Technol 289:. https://doi.org/10.1016/j.jmatprotec.2020.116932

21. Zhang R, Shi Z, Shao Z, et al (2021) Biaxial test method for determination of FLCs and FFLCs for sheet metals: validation against standard Nakajima method. Int J Mech Sci 209:106694. https://doi.org/10.1016/j.ijmecsci.2021.106694

22. Lou Y, Huh H, Lim S, Pack K (2012) New ductile fracture criterion for prediction of fracture forming limit diagrams of sheet metals. Int J Solids Struct 49:3605-3615.

https://doi.org/10.1016/j.ijsolstr.2012.02.016

23. Alipour M, Torabi MA, Sareban M, et al (2020) Finite element and experimental method for 
analyzing the effects of martensite morphologies on the formability of DP steels. Mech Based Des Struct Mach 48:525-541

24. He J, Cedric Xia Z, Zeng D, Li S (2013) Forming limits of sheet metal after continuous-bendingunder-tension loading. J Eng Mater Technol 135:031009. https://doi.org/10.1115/1.4023676

25. Isik K, Silva MB, Tekkaya AE, Martins PAF (2014) Formability limits by a fracture in sheet metal forming. J Mater Process Technol 214:1557-1565.

https://doi.org/10.1016/j.jmatprotec.2014.02.026

26. Güler B, Efe M (2017) Large strain cruciform biaxial testing for FLC detection. AIP Conf Proc 1896:. https://doi.org/10.1063/1.5007975

27. Banabic D, Barlat F, Cazacu O, Kuwabara T (2020) Advances in anisotropy of plastic behavior and formability of sheet metals. Int J Mater Form 13:749-787

28. Jeswiet J, Micari F, Hirt G, et al (2005) Asymmetric single point incremental forming of sheet metal. CIRP Ann - Manuf Technol 54:88-114. https://doi.org/10.1016/S0007-8506(07)60021-3

29. Stoughton TB, Yoon JW (2011) A new approach for failure criterion for sheet metals. Int J Plast 27:440-459. https://doi.org/10.1016/j.ijplas.2010.07.004

30. Hu Q, Zhang F, Li X, Chen J (2018) Overview on the prediction models for sheet metal forming failure: necking and ductile fracture. Acta Mech Solida Sin 31:259-289.

https://doi.org/10.1007/s10338-018-0026-6

31. Wierzbicki T, Bao Y, Lee YW, Bai Y (2005) Calibration and evaluation of seven fracture models. Int J Mech Sci 47:719-743. https://doi.org/10.1016/j.ijmecsci.2005.03.003

32. Cockcroft MG, Latham DJ (1968) Ductility and the workability of metals. J. Inst. Met. 96:33-39

33. Talebi-Ghadikolaee H, Naeini HM, Mirnia MJ, et al (2020) Ductile fracture prediction of AA6061-T6 in roll forming process. Mech Mater 148:103498. https://doi.org/10.1016/j.mechmat.2020.103498

34. Brozzo P, Deluca B, Rendina D (1972) A new method for the prediction of formability limits in metal sheets. In: Sheet Metal Forming and Formability: Proceedings of the 7th biennial Conference of the International Deep Drawing Research group

35. Mahalle G, Kotkunde N, Gupta AK, Singh SK (2020) Comparative assessment of failure strain predictions using ductile damage criteria for warm stretch forming of IN718 alloy. Int J Mater Form. https://doi.org/10.1007/s12289-020-01588-3

36. Ayada M (1987) Central bursting in extrusion of inhomogeneous materials. In: Proceedings of 2nd International Conference on Technology for Plasticity,. Stuttgart, Germany, pp 553-558

37. Talebi-Ghadikolaee H, Naeini HM, Mirnia MJ, et al (2020) Fracture analysis on U-bending of AA6061 aluminum alloy sheet using phenomenological ductile fracture criteria. Thin-Walled Struct 148:106566. https://doi.org/10.1016/j.tws.2019.106566

38. Rice JR, Tracey DM (1969) On the ductile enlargement of voids in triaxial stress fields. J Mech Phys Solids 17:201-217. https://doi.org/10.1016/0022-5096(69)90033-7

39. Hu XH, Choi KS, Sun X, Golovashchenko SF (2014) Edge fracture prediction of traditional and advanced trimming processes for AA6111-T4 sheets. J Manuf Sci Eng 136:021016. https://doi.org/10.1115/1.4026273

40. Fu Z, Chen W, Tian X, Hu B (2014) Modeling and simulation for multiple-step incremental airbending forming of sheet metal. Int J Adv Manuf Technol 72:561-570. https://doi.org/10.1007/s00170-014-5708-8

41. ASTM International (2009) ASTM E8/E8M-13 standard test methods for tension testing of metallic materials

42. Ling Y (2004) Uniaxial true stress-strain after necking. AMP J Technol 5:37-48

43. Yang SY, Tong W (2009) A finite element analysis of a tapered flat sheet tensile specimen. Exp Mech 49:317-330. https://doi.org/10.1007/s11340-009-9241-x

44. Wang L, Tong W (2015) Identification of post-necking strain hardening behavior of thin sheet metals from image-based surface strain data in uniaxial tension tests. Int J Solids Struct 75-76:1231. https://doi.org/10.1016/j.ijsolstr.2015.04.038 